\title{
Phytochemicals in bioenergy crops
}

\author{
Marta Oleszek (D) - Iwona Kowalska • Wieslaw Oleszek
}

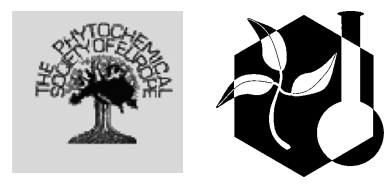

Received: 3 October 2018/ Accepted: 30 July 2019/Published online: 9 August 2019

(C) The Author(s) 2019

\begin{abstract}
The use of natural compounds derived from agricultural crops and other plants as health promoting chemicals gains tremendous growing interest in various industrial sectors as well as among people worldwide. These chemicals have been more and more employed by the food industry as food additives, functional food ingredients, nutraceuticals, by feedstuffs industry, but also by the cosmetic and pharmaceutical industries. The general idea for this interest is to use natural products as potential alternatives to synthetic chemicals. On the other hand, some plants characterized by high yield and being used as energy crops also contained significant amount of bioactive compounds. This review focuses on the wide spectrum of the phytochemicals present in available biomass plants. It is supposed that extraction of bioactive chemicals from energy crops before their energetic use may increase economical effectiveness, providing simultaneously a double benefit in the form of phytochemicals and bioenergy as value added products. This remains in line with bioeconomy, which is defined by European Commission as "the
\end{abstract}

M. Oleszek $(\bowtie)$

Institute of Agrophysics, Polish Academy of Sciences, Doświadczalna 4, 20-290 Lublin, Poland

e-mail: m.oleszek@ipan.lublin.pl

I. Kowalska · W. Oleszek

Institute of Soil Science and Plant Cultivation, State

Research Institute, Czartoryskich 8, 24-100 Pulawy,

Poland production of renewable biological resources and the conversion of these resources and waste streams into value added products, such as food, feed, bio-based products and bioenergy". However, the issue is still a challenging effort due to the high costs, technology readiness and regulatory hurdles.

Keywords Biomass - Biomass phytochemicals . Natural products source $\cdot$ Biorefinery concept

\section{Introduction}

Increase in food, feed and energy demands stressed to explore sustainable opportunities for the combined production of fuels, food and phytochemicals (Parajuli et al. 2017). Energy crops and wood were generally used as a feedstock for energy production, due to their high biomass yield, great calorific value, as well as low agronomic input. They find application in the production of biofuels, both by direct combustion and biological fermentation, i.e. biogas and bio-ethanol (Oleszek and Matyka 2017). Nonetheless, available literature data have proven that many of them have a potential to become suitable source of valuable phytochemicals for industrial use, because of substantial concentration of antioxidants and other biologically active compounds (Duynisveld et al. 1990; Veitch et al. 2010; Parveen et al. 2011; Oleszek and 
Krzemińska 2017). Moreover, some compounds usable in the pharmaceutical, cosmetic and food sectors may be produced and extracted during various pretreatment of lignocellulose, main component of all energy biomasses. Such plants versatility and the wide use of their products indicate that energy crops and woody biomass are suitable for the development of a bio-refinery concept, where the production of bioenergy/biofuels is preceded by recovery of bio-based compounds and coupled with generation of other value-added products. It would allow the comprehensive usage of crops, to maximize the benefits from the unit of arable land area of their cultivation and to improve the profitability of their processing (Montastruc et al. 2011; Corno et al. 2014). Moreover, it has been shown that extraction of valuable compounds may be a good method of biomass pretreatment, enhancing its suitability for subsequent bioenergy production (Attard et al. 2015). Furthermore, some phytochemicals contained in energy crops can influence on the efficiency of bioenergy production in biotechnological processes involved microorganisms, such as methane or ethanol fermentation (Popp et al. 2016). Therefore, removal of phytochemicals from biomass by extraction may improve biomass suitability. Clear advantage of multi-product plants has been revealed, essentially pointing to the fact that singleproduct plants are not feasible (Tsakalova et al. 2014). The selection of an appropriate process for combined recovery of materials and energy from biomass depends primarily on its properties, the expected forms of bioenergy and bio-products, and the economic feasibility (Wang 2013).

The purpose of this paper is to review the literature of bioactive compounds contained in energy crops and woody biomass, their properties, methods of extraction and analysis, as well as potential application in pharmaceutical, cosmetic and food industry. It was intended to show other possibilities of use the biomass instead of or in combination with energy production.

\section{Herbaceous energy crops}

\section{Maize (Zea mays L.)}

Maize (Zea mays L.) belongs to the family of grasses (Poaceae); (Fig. 1). This plant is one of the three the highest output and cultivated crops around the world (Qi et al. 2018). Maize is not only a basic element of human diet, but also an important animal feed and raw material for many manufactories (Nile and Park 2014). Moreover, it is also main feedstock for biogas production, particularly in the Central Europe (Herrmann 2013; Oleszek and Matyka 2018).

Both maize seeds, as well as vegetative parts of plant contain many secondary metabolites, such as phenolics, flavonoids, carotenoids and phytosterols. Selected compounds identified previously in maize were listed in the Table 1. Many of them are classified as strong antioxidants. Interestingly, Dewanto et al. (2002) proved that thermal processing significantly elevated the total antioxidant activity of corn by $44 \%$, although $25 \%$ loss of vitamin C. Simultaneously, the concentration of phenolic compounds significantly increased. These findings indicated that most of the antioxidant activity comes from the natural combination of phytochemicals such as ferulic acids and other phenolics, not only from presence of vitamin C. It denies the popular notion that processed fruits and vegetables have lower nutritional value than fresh ones. Vazquez-Olivo et al. (2017) indicated that phenolic acids and lignin from maize stover, remaining after maize production, exhibit high antioxidant properties and should be used for valorization of this biomass. Nile and Park (2014) isolated some phenolic acids and anthocyanins from maize kernel to
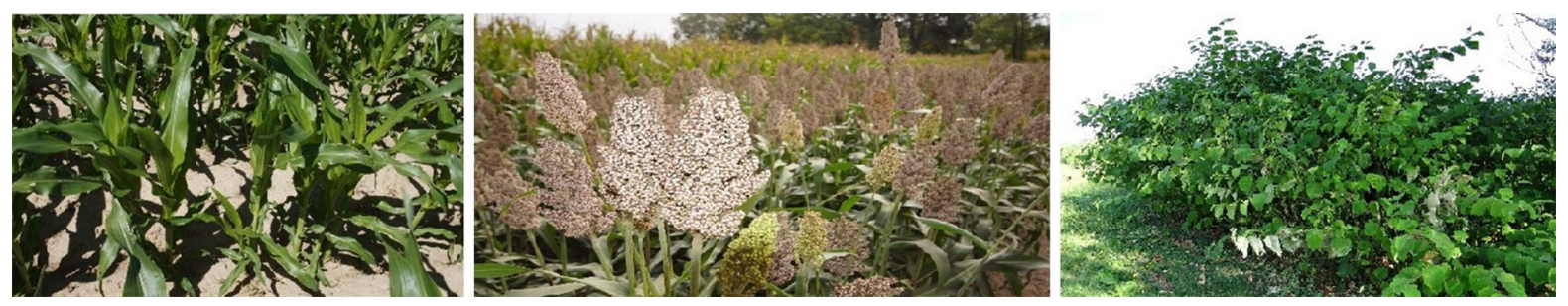

Fig. 1 Zea mays L., Sorghum spp. and Poligonum sachalinensis 
Table 1 Phytochemicals identified in Zea mays L

\begin{tabular}{|c|c|c|}
\hline $\begin{array}{l}\text { Part of } \\
\text { plants }\end{array}$ & Metabolites & References \\
\hline \multirow[t]{2}{*}{ Kernels } & $\begin{array}{l}\text { Protocatechuic acid, vanillic acid, 2,4,6-trihydroxybenzoicacid, } p \text {-hydroxycinnamic acid, } \\
\text { ferulic acid, hirsutrin, 3'-methoxyhirsutrin, cyanidin-3-glucoside, pelargonidin-3-glucoside, } \\
\text { peonidin-3-glucoside, }\end{array}$ & Nile and Park (2014) \\
\hline & $\begin{array}{l}\text { Quinic acid, 1-O-caffeoylquinic acid, 2- } O \text {-caffeoylquinic acid, 3- } O \text {-caffeoylquinic acid, 4- } O \text { - } \\
\text { caffeoylquinic acid, 5- } O \text {-caffeoylquinic acid, hydroxychlorogenic acid, 3-O-feruloylquinic } \\
\text { acid, 5- } O \text {-feruloylquinic acid, 5- } p \text {-coumaroylquinic acid }\end{array}$ & $\begin{array}{l}\text { Atanasova-Penichon } \\
\text { et al. (2014) }\end{array}$ \\
\hline $\begin{array}{l}\text { Stigma } \\
\text { maydis }\end{array}$ & Stigmene A-F & Qi et al. (2018) \\
\hline Cobs & Phydroxybenzoic, protocatechuic, $p$-coumaric, and ferulic acids & Dewanto et al. (2002) \\
\hline Roots & Zealactone, zeapyranolactone, 5-deoxystrigol, heliolactone, methyl ester of carlactonoic acid & $\begin{array}{l}\text { Charnikhova et al. } \\
\text { (2018) }\end{array}$ \\
\hline Stovers & Ferulic acid, $p$-coumaric acid & $\begin{array}{l}\text { Vazquez-Olivo et al. } \\
\text { (2017) }\end{array}$ \\
\hline
\end{tabular}

determine their antioxidant, $\alpha$-glucosidase and xanthine oxidase inhibitory activity. The authors proved that all the phenolic compounds revealed significant biological activities with all examined parameters.

Many maize phytochemicals are its natural protectants, which enhance the plant resistance to pathogens. Atanasova-Penichon et al. (2014) stated that bioactive compounds contained in maize kernel were able to reduce the contamination of grain with fumonisin mycotoxins secreted by Fusarium verticillioides. Chlorogenic acid was identified as the main compounds responsible for antifungal activity. Similar results were obtained by Nesci and Etcheverry (2006), who investigated the effect of natural maize phytochemicals, trans-cinnamic acid (CA) and ferulic acid (FA) on the growth of Aspergillus flavus and alfatoxin production. In this work, the authors proved that CA and FA can be considered as effective fungitoxicants for A. flavus and A. parasiticus in in vitro assay. Wang et al. (2014) evaluated antioxidant and antigenotoxic activities of corn tassel extracts (CTTs). The major bioactive compounds belonged to flavonoids (1.67\%), saponins (2.41\%) and polysaccharides (4.76\%) group. CTTs extract exhibited antioxidant activity and inhibited the proliferation of human gastric cancer cells. Anticancer activity of Zea mays leaf extracts was stated by Balasubramanian and Padma (2013). The best effect was exerted by the methanolic extract followed by the aqueous and chloroform extracts. Other valuable compounds from maize are sesquiterpenes. Qi et al. (2018) reported that during industrial processing of maize a vast amount of residues including stigma maydis was generated, which is generally regarded as a waste and discarded. From this material, the authors isolated and identified five new macrocarpene-type sesquiterpenes, named stigmenes A-E, along with a known analogue stigmene F. Furthermore, it has been proven that, these compounds exhibited the inhibitory effect of amyloid- $\beta$ (A $\beta$ ) aggregation, which may give the chance for their application against Alzheimer's disease (AD), an agerelated neurodegenerative disease. The latest study concern the new class of plant hormones included in maize roots, namely the strigolactones, which play important role in the regulation of plant architecture, and are also exuded by plants into the rhizosphere. Ahmed (2018) stated the allelopatic effect of maize crude extract against seed germination and seedling growth of Phalaris minor, Helianthus annuus, Triticumaestivum, Sorghum halepense and Zea mays. Aqueous shoot and root extract contained tannins, phlobatannins, flavonoids, terpenoids, alkaloids and saponins. It has given hope for potential use as natural herbicides to reduce the adverse effects of using synthetic compounds.

Maize is also potential feedstock for natural waxes. Attard et al. (2015) investigated the biorefinery concept, where supercritical extraction was applied for obtaining of waxes from maize stovers. The extraction was used as initial step in biorefinery plant, before fermentation of biomass. It has been proved that such extraction is not only important way for obtaining of waxes, but also good method of biomass pretreatment for the production of 2 nd generation 
biofuels. Wax from maize can be used in the production of nutraceuticals, pharmaceuticals, cosmetics and as a natural defoaming agent in washing machine, due to replace environmentally hazardous formulations.

\section{Sorghum (Sorghum spp.)}

Sorghum (Sorghum spp.) is one of the most important crops in the world (Fig. 1). This is gluten-free grain crop ranked as the fifth most produced cereal crop globally. This plant is drought tolerant and has been grown in semiarid regions. Seeds are used as a food source in many areas. It produces a large variety of secondary metabolites, including phenolic acids, flavonoids, and condensed tannins, phytosterols, policosanols and bioactive peptides (Awika and Rooney 2004; Dykes et al. 2009; Duodu and Awika 2019). Their types and quantities are affected by the genotype. It was documented that this species contains number of phenolic acids including $p$-hydroxybenzoic, vanillic, caffeic, syringic, ferulic, $p$-coumaric and gentisic acid as well as some aldehydes: $p$ hydroxybenzaldehyde, syringaldehyde and vanillin (Sène et al. 2001). The total phenol concentration reached $1.1-1.5 \%$ of the root dry weight and $1.1-2.2 \%$ of the aerial part dry weight.

As for the flavonoids, luteolin and apigenin were the two flavones that were identified and quantified in the sorghum varieties (Dykes et al. 2011). Flavonoid phytoalexins, such as 3-deoxyanthocyanidins, are synthesized by sorghum after treatment with jasmonic acid, as an essential component of active defense mechanisms (Du et al. 2010; Meyer et al. 2016). The 3-deoxyanthocyanins have been identified as orange luteolinidin and the yellow apigeninidin.

Not much information has been available in literature on the chemical composition of sorghum straw, which is major by-product, which can be used as biomass. Some sorghum species may contain cyanogenic compounds, in the form of glycosides (dhurrin) or alkaloids (hordenin) (Funnell-Harris et al. 2008). Dhurrin, a major secondary product of aerial shoot sorghum plant, is located almost exclusively in the epidermis and is recognized as a major insect defense component (D'Mello 2000; Kojima and Conn 1982). Dhurrin on enzyme activity readily yields hydrogen cyanid ( $\mathrm{HCN}$ ) strongly toxic to animals.
Some phytochemicals are recognized as important in allelopathic potential of sorghum. Besides of phenolic acids and aldehydes that can be secreted by the root system, the most important in this respect seem to be hydrophobic sorgoleone \{2-hydroxy-5methoxy-e-[(8Z,11Z-8,11,14-pentadecatriene]-p-benzoquinone $\}$ and its analogues (Soltys et al. 2010). There is no information available on its appearance in the sorghum straw. In this respect more research is needed. For using of sorghum by-products as a potential source of bioactive compounds there is a need to develop efficient green extraction methods. Conventional methods using refluxing, hotwater, maceration and soxhlet extraction are tedious, low efficient and not environmentally friendly (Azmir et al. 2013). More recently some other high efficient methods including ultrasonic, pulsed electric field, microwave, pressurized water and ultrasonic assisted extraction has been developed (Pasrija and Anandharamakrishnan 2015; Hou et al. 2016; Luo et al. 2018).

\section{Giant knotweed (Fallopia sachalinensis, Reynoutria sachalinensis, Polygonum sachalinense)}

Giant knotweed known as Fallopia sachalinensis (syn. Reynoutria sachalinensis or Polygonum sachalinense) is a perennial polyploid species, which was introduced into Europe in the 20th century, mainly as a garden ornamental (Koštálová et al. 2014); (Fig. 1). Biomass of this plant was investigated previously as feedstock for production of energy and activated carbons (Strašil and Kára 2010; Fałtynowicz et al. 2015). This plant produces many secondary metabolites (Table 2) that are medically valuable, such as and phenylpropanoid glycosides. stilbenes, anthraquinones, flavonols, flavonoids and flavanol gallate dimers (Kumagai et al. 2005; Kawai et al. 2006; Fan et al. 2009). Lachowicz et al. (2019) identified seventy-one potential healthpromoting compounds in leaves and rhizomes of Fallopia sachalinensis, using the ultra-performance liquid chromatography photodiode detector-quadrupole/time-of-flight mass spectrometry (UPLC-PDAQ/TOF-MS) method. Among them, there were 15 phenolic acids, 12 flavones and flavonols, 11 flavan-3ols, 8 stilbenes, 9 carotenoids, 13 chlorophylls and 3 triterpenoids. Moreover, three anthraquinones (emodin, emodin-8- $O$ - $\beta$-D-glucopyranoside and physcion- 
Table 2 Phytochemicals identified in Fallopia sachalinensis

\begin{tabular}{|c|c|c|}
\hline $\begin{array}{l}\text { Part of } \\
\text { plants }\end{array}$ & Metabolites & References \\
\hline Roots & $\begin{array}{l}\text { Procyanidins, flavanol gallate dimers (resveratroloside, piceid, emodin glucoside, piceatannol } \\
\text { glucoside) }\end{array}$ & Fan et al. (2009) \\
\hline \multirow[t]{4}{*}{ Leaves } & Phenolics & $\begin{array}{l}\text { Hromádková } \\
\text { et al. (2010) }\end{array}$ \\
\hline & $\begin{array}{l}\text { Seventy-one secondary metabolites: forty-six polyphenolic compounds ( } 15 \text { phenolic acids, } 12 \\
\text { flavones and flavonols, } 11 \text { flavan-3-ols and } 8 \text { stilbenes); } 9 \text { carotenoids, } 13 \text { chlorophylls, } 3 \\
\text { triterpenoids }\end{array}$ & $\begin{array}{l}\text { Lachowicz et al. } \\
\text { (2019) }\end{array}$ \\
\hline & Phenylacetonitrile & $\begin{array}{l}\text { Noge and } \\
\text { Tamogami } \\
(2013)\end{array}$ \\
\hline & $\begin{array}{l}\text { Phenylacetonitrile, terpenes: (E)- } \beta \text {-ocimene, linalool, (E)-4,8-dimethyl-1,3,7-nonatriene (DMNT), } \\
\text { (E,E)- } \alpha \text {-farnesene }\end{array}$ & $\begin{array}{l}\text { Noge et al. } \\
\text { (2011) }\end{array}$ \\
\hline \multirow[t]{2}{*}{ Flowers } & $\begin{array}{l}\text { Anthraquinones (emodin, emodin- } 8-O-\beta \text {-D-glucopyranoside and physcion- } 8 \text { - } O \text { - } \beta \text {-D-glucopyranoside) } \\
\text { and flavonoids (quercetin-3- } O \text { - } \alpha \text {-L-arabinofuranoside, quercetin-3- } O \text { - } \beta \text {-D-galactopyranoside, } \\
\text { quercetin-3- } O \text { - } \beta \text {-D-glucuronopyranoside) }\end{array}$ & $\begin{array}{l}\text { Zhang et al. } \\
\text { (2005) }\end{array}$ \\
\hline & $\begin{array}{l}\text { Campesterol, 1-decanol, } \beta \text {-amyrin, dammaran-3 } \beta \text {-ol, daucosterol, ergosterol peroxide, emodin } 8 \text { - } O \text { - } \\
\beta \text {-D-glucopyranoside, quercetin, isoquercitrin }\end{array}$ & \\
\hline \multirow[t]{2}{*}{ Stems } & Flavanol gallate dimers (resveratroloside, piceid, emodin glucoside, piceatannol glucoside) & Fan et al. (2009) \\
\hline & Campesterol, emodin8- $O$ - $\beta$-D-glucopyranoside, quercetin, and isoquercitrin & $\begin{array}{l}\text { Eom et al. } \\
\text { (2017) }\end{array}$ \\
\hline \multirow[t]{4}{*}{ Rhizomes } & Emodin, physcion, glycosides of 9,10-anthraquinone derivatives & $\begin{array}{l}\text { Inoue et al. } \\
\quad(1992)\end{array}$ \\
\hline & Polydatin (piceid) & Li et al. (2013) \\
\hline & $\begin{array}{l}\text { Polyphenolic compounds (phenolic acids, flavones and flavonols, flavan-3-ols, stilbenes); } \\
\text { carotenoids, chlorophylls, triterpenoids }\end{array}$ & $\begin{array}{l}\text { Lachowicz et al. } \\
\text { (2019) }\end{array}$ \\
\hline & $\begin{array}{l}\text { Anthraquinones (emodin and physcion), flavan-3-ols, phenylpropanoid esters, tatariside } \mathrm{B} \text {, } \\
\text { hydropiperoside, vanicoside A, B, C; 3,6- } O \text {-di- } p \text {-coumaroyl- } \beta \text {-fructofuranosyl- }(2 \rightarrow 1)-\left(2^{\prime}-O \text { - }\right. \\
\text { acetyl- } 6^{\prime}-O \text {-feruloyl)- } \beta \text { glucopyranoside, hydroxycinnamic sucrose esters }\end{array}$ & $\begin{array}{l}\text { Nawrot-Hadzik } \\
\text { et al. (2018) }\end{array}$ \\
\hline Sprouts & Stilbenes (resveratrol, piceid) catechins (catechin, epicatechin) & $\begin{array}{l}\text { Vrchotova et al. } \\
\text { (2007) }\end{array}$ \\
\hline \multirow[t]{3}{*}{$\begin{array}{r}\text { Aerial } \\
\text { parts }\end{array}$} & Emodin, physcion, glycosides of 9,10-anthraquinone derivatives & $\begin{array}{l}\text { Inoue et al. } \\
\quad(1992)\end{array}$ \\
\hline & $\begin{array}{l}\text { Glycosylated derivatives of the flavonols kaempferol, quercetin, myricetin, and of the flavones } \\
\text { apigenin and luteolin }\end{array}$ & $\begin{array}{l}\text { Kim et al. } \\
\text { (2000) }\end{array}$ \\
\hline & $\begin{array}{l}\text { Rutin, chrysophanol, 6-OH-emodin, emodin, hyperoside, isoquercetin, trifolin, austragalin, } \\
\text { polygonimitin } \mathrm{B} \text {, chrysophanol, emodin-8-O-glucoside, neomangiferin, mangiferin quercetin, } \\
\text { kaempferol I3-II8-biapigenin, apigenin }\end{array}$ & $\begin{array}{l}\text { Yu and Zhang } \\
(2011)\end{array}$ \\
\hline
\end{tabular}

8- $O$ - $\beta$-D-glucopyranoside) and three flavonoids (quercetin-3- $O-\alpha$-L-arabinofuranoside, quercetin-3-O- $\beta$-Dgalactopyranoside and quercetin-3- $O-\beta$-D-glucuronopyranoside) were identified in the flowers of P. sachalinensis (Zhang et al. 2005). The emodin, physcion, and glycosides of 9,10-anthraquinone derivatives have been detected also by Inoue et al. (1992), both in the rhizomes and in the aerial part of Fallopia sachalinensis. Due to the presence of natural bioactive compounds, giant knotweed is traditionally used in Japan and China as herbal medicine (Konstantinidou-Doltsinis et al. 2006). Secondary metabolites from Fallopia spp. inhibit denitrification and exhibit antioxidant activity (Bardon et al. 2014). The major denitrification inhibitors are B-type procyanidins from the proanthocyanidin class of flavonoids (Bardon et al. 2016). Kim et al. (2000) isolated and identified twenty-one flavonoid compounds with 
Table 3 Phytochemicals identified in Fallopia japonica

\begin{tabular}{|c|c|c|}
\hline $\begin{array}{l}\text { Part of } \\
\text { plants }\end{array}$ & Metabolites & References \\
\hline \multirow[t]{6}{*}{ Roots } & $\begin{array}{l}\text { Resveratrol (trans-3,5,4'-trihydroxystilbene), hydroxyresveratrol, } \\
\text { resveratroloside, piceid (polydatin), piceatannol, piceatannol glucoside, } \\
\text { transresveratrol derivatives and cis-resveratrol derivatives }\end{array}$ & $\begin{array}{l}\text { Vastano et al. (2000), Xiao et al. (2000) } \\
\text { and Jayatilake et al. (1993) }\end{array}$ \\
\hline & $\begin{array}{l}\text { Phenol glycosides: quercetin and its glycosides, kaempferol-3- } O-\alpha-\mathrm{L}- \\
\text { rhamnoside, }(-) \text {-epicatechin-5- } O-\beta \text {-D-glucopyranoside, quercetin, }(+)- \\
\text { catechin, apigenin }\end{array}$ & Huang et al. (2008) \\
\hline & $\begin{array}{l}\text { 2-methoxy-6-acetyl-7-methyljuglone, protocatechuic acid, } 2,5 \text {-dimethyl-7- } \\
\text { hydroxy chromone, torachrysone-8- } O \text { - } \beta \text {-D-glucoside, } 7 \text {-hydroxy-4- } \\
\text { methoxy-5-methylcoumarine, 1-(3- } O \text { - } \beta \text {-D-glucopyranosyl-4,5- } \\
\text { dihydroxyphenyl)-ethanone }\end{array}$ & Kimura et al. (1983) \\
\hline & Chlorogenic acid, tachioside, isotachioside & Lin et al. (2010) \\
\hline & $\begin{array}{l}\text { Anthaquinones chrysophanol, physicion, emodin, emodin- } 8-O \text {-D-glucosidem; } \\
\text { the phenolics physcion- } 8-O \text {-D-glucoside, fallacinol, citerorosein, questin, } \\
\text { questinol, protocatechuic acid, }(+) \text {-catechin Catechins: }(-) \text {-epicatechin-5- } \\
O-\beta \text {-D-glucopyranoside, }(+) \text {-catechin and its glucoside }\end{array}$ & Bais et al. (2003) \\
\hline & $\begin{array}{l}\text { (-)-lyoniresinol-2a-sulfate, }(+) \text {-isolaricireinol-2a-sulfate, } 1-\left(3^{\prime}, 5^{\prime}-\right. \\
\text { dihydroxyphenyl)-2-(4"-hydroxyphenyl)-ethane-1,2-diol, gallic acid and } \\
\text { derivative, tryptophan, 2,6-dihydroxybenzoic acid }\end{array}$ & Xiao et al. (2000) and Xiao et al. (2003) \\
\hline \multirow[t]{3}{*}{ Leaves } & Resveratrol & Chen et al. $(2013 a, b)$ \\
\hline & 2-hexenal, n-hexanal, 3-hexen-1-ol, 1-penten-3-ol and 2-penten-1-ol & Kim et al. (2005) \\
\hline & $\begin{array}{l}\text { Seventy-one secondary metabolites: forty-six polyphenolic compounds (15 } \\
\text { phenolic acids, } 12 \text { flavones and flavonols, } 11 \text { flavan-3-ols and } 8 \text { stilbenes); } \\
\text { carotenoids (9), chlorophylls (13) and triterpenoids (3) }\end{array}$ & Lachowicz et al. (2019) \\
\hline Stems & Resveratrol & Chen et al. $(2013 a, b)$ \\
\hline \multirow[t]{3}{*}{ Rhizomes } & $\begin{array}{l}\text { Emodin and its derivatives, anthraglycosides } \mathrm{A} \text { and } \mathrm{B} \text {, chrysophanol, } \\
\text { physcion, fallacinol, citreorosein, rhein, questin and questinol }\end{array}$ & $\begin{array}{l}\text { Yang et al. (2001) and Zhang et al. } \\
\text { (2007) }\end{array}$ \\
\hline & $\begin{array}{l}\text { Polyphenolic compounds (phenolic acids, flavones and flavonols, flavan-3- } \\
\text { ols, stilbenes); carotenoids, chlorophylls, triterpenoids }\end{array}$ & Lachowicz et al. (2019) \\
\hline & $\begin{array}{l}\text { Stilbenes (piceid and resveratrol), anthraquinones (emodin and physcion), } \\
\text { flavan-3-ols, phenylpropanoid esters, tatariside B, hydropiperoside, } \\
\text { vanicoside A, B, C; 3,6- } O \text {-di- } p \text {-coumaroyl- } \beta \text {-fructofuranosyl- }(2 \rightarrow 1)-\left(2^{\prime}-\right. \\
\text { O-acetyl-6'-O-feruloyl)- } \beta \text { glucopyranoside, hydroxycinnamic sucrose esters }\end{array}$ & Nawrot-Hadzik et al. (2018) \\
\hline Seedling & Anthocyanin & Yamaguchi et al. (2000) \\
\hline
\end{tabular}

antioxidant properties from five Fallopia species. They were glycosylated derivatives of the flavonols: kaempferol, quercetin, myricetin and of the flavones: apigenin and luteolin.

Japanese knotweed (Fallopia japonica, Reynoutria japonica, Polygonum cuspidatum)

Japanese knotweed (Fallopia japonica, also known as Polygonum cuspidatum) is a rhizomatous, herbaceous perennial, which was introduced to the United States during the late eighteenth century as an ornamental and as a source of fodder (Barney et al. 2006). Japanese knotweed has high productivity (Aguilera et al. 2010) and high concentrations of secondary metabolites, including stilbens, anthraquinones, tannins, lignans, anthocyanins, sterols and phenethyl alcohols (Table 3); (Fan et al. 2009; Miyagi et al. 2010). Resveratrol (stilben) and emodin (an anthraquinone) are listed as the major active ingredients of this plant (El-Readi et al. 2016). Resveratrol concentrations in Japanese knotweed range from 2.96 to $3.77 \mathrm{mg} / \mathrm{g}$ dry weight (Vastano et al. 2000). It has been proven that roots contain its much higher amount than 
the stem and leaf (Chen et al. 2013a, b). Weston et al. (2005) stated that the amount of stilbenes, including resveratrol, within the roots of $P$. cuspidatum was even higher than concentrations reported in red grapes and wine. Moreover, the roots of $F$. japonica has been reported to contain a large number of stilbens, showing high antioxidant and health promoting activities, frequently found as glycosides and sulfates (Vastano et al. 2000; Xiao et al. 2000). Additionally, phenol glycosides, kaempferol-3- $O-\alpha$-L-rhamnoside, (-)-epicatechin-5- $O-\beta$-D-glucopyranoside as well as quercetin, (+)-catechin, apigenin and their derivatives were found in the roots (Kimura et al. 1983; Huang et al. 2008). Anthraquinones, including emodin and its derivatives, anthraglycosides A and B, chrysophanol, physcion, fallacinol, citreorosein, rhein, questin and questinol, are important chemical constituents also in the rhizomes and aerial part of plant (Yang et al. 2001; Kim et al. 2005; Zhang et al. 2007). A total of 18 volatile compounds were identified in the extract of $F$. japonica leaves The major phytochemicals were n-hexanal, 2-hexenal, 3-hexen-1-ol, 1-penten-3-ol and 2-penten-1-ol (Kim et al. 2005). Lachowicz et al. (2019) described in $F$. japonica leaves forty-six polyphenolic compounds and 25 new compounds belonging to carotenoids, chlorophylls and triterpenoids using UPLC-PDA-Q/TOF-MS method.

Fallopia japonica has been used in Chinese medicine, where emodin is regarded as a qualitycontrol index. Pharmacological studies have evaluated several aspects of Fallopia japonica extract including antioxidant (Pan et al. 2007), antiviral (Lin et al. 2010), anti-inflammatory (Bralley et al. 2008) and anticancer activities (Feng et al. 2006). Japanese knotweed extract has ability to inhibit NF- $\mathrm{BB}$ and neutrophil infiltration animal models of edema (Bralley et al. 2008). Its anticancer activity has different molecular modes of action and mechanisms through their ability to modulate the proliferation, apoptosis,

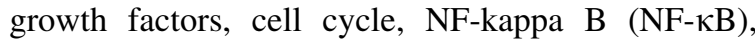
protein kinase $\mathrm{C}(\mathrm{PKC})$, and mitogen-activated protein kinase (MAPK) signaling cascades (Aggarwal and Shishodia 2006). Kimura and Okuda (2001) showed that the phytoalexine resveratrol isolated from $P$. cuspidatum roots, has received considerable attention for its anti-cancer properties. Kimura et al. (1995) demonstrated that liver peroxidation in rats was found to be mitigated by several components of $P$. cuspidatum root extracts; namely the stilbenes piceid, resveratrol and 2,3,5,4'-tetrahydroxy stilbene-2- $O$-Dglucoside. Song et al. (2006) stated that crude methanolic extract from roots of $P$. cuspidatum, containing alkaloids, sterol/terpenes, tannins, flavonoids, and carbohydrates, inhibited the bacterial viability and may be useful for the control of dental plaque and subsequent dental caries formation.

\section{Jerusalem artichoke (Helianthus tuberosus L.)}

Helianthus tuberosus L. (known as Jerusalem artichoke), which belong to the Asteraceae family, is a native plant of North America. It has recently been recognized as a promising biomass for bioeconomy development, with a number of advantages over conventional crops (Yang et al. 2015); (Fig. 2). Jerusalem artichoke is valuable crop for its applications as functional food and bioactive ingredient sources (Yang et al. 2015). Besides, its yield potential and low requirements meant that it could be of interest in the energy sector (Kowalczyk-Juśko et al. 2012). Recently, rapidly growing interest is for the use of Jerusalem artichoke tubers, which are rich in inulin, as raw materials for bioethanol production (Celp et al. 2012; Song et al. 2017). Jerusalem artichoke also has potential for generating a variety chemicals, such as citric acid, 2,3-butanediol (Liu et al. 2010), butyric acid (Huang et al. 2011) and sorbitol (Wei et al. 2001).
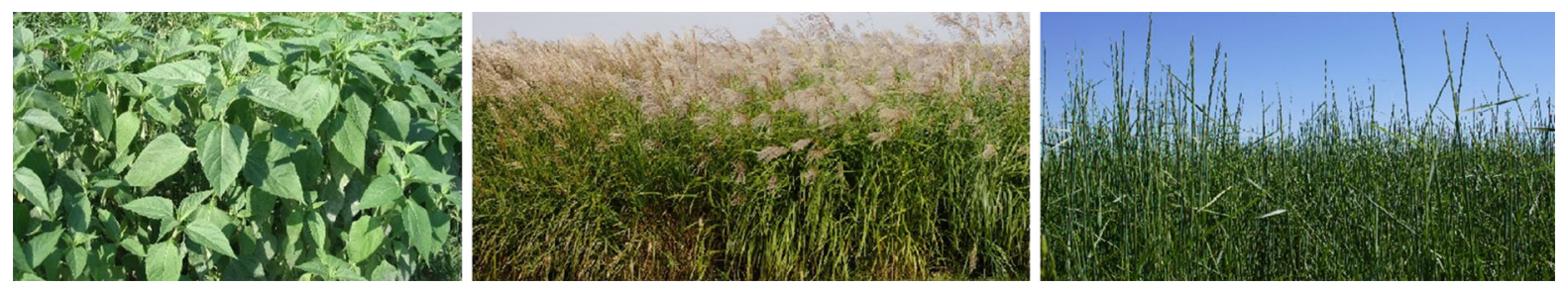

Fig. 2 Heliantus tuberosus, Miscanthus $\times$ gigantheus, Phlaris arundinacea $\mathrm{L}$ 
A number of bioactive compounds of medicinal significance have been isolated from the aerial parts of Jerusalem artichoke, indicating anticancer, antidiabetic, antioxidant, antifungal and antimicrobial activities and other medicinal effects (Ahmed et al. 2005; Baba et al. 2005; Liu et al. 2007; Han et al. 2010; Yuan et al. 2012; Al-Snafi 2018). Two flavone glucosides, kaempferol 3-O-glucoside and quercetin 7-O-glucoside were isolated from the leaves of Helianthus tuberosus by Chae et al. (2002). The results obtained by Chen et al. (2013a, b) imply that Jerusalem artichoke leaves might be a potential source of natural fungicides. The extracts of antifungal compounds and phenolic acids were investigated for their potential use in enhancing preservation of fruits and vegetables during storage. Crude leaf extract or $n$-butanol fraction was active against Botrytis cinerea, Colletotrichumgloeosporioides, Phytophthoracapsici and Rhizoctoniacerealis (Chen et al. 2013a, b). Six phenolic acids were separated using in vitro activity-guided fractionation. Among them, caffeic acid, 3,4-dicaffeoylquinic acid and 1,5-dicaffeoylquinic acid played a dominant role and were active in bioassays against Gibberellazeae. The main constituents are chlorogenic and isochlorogenic acids, which have good antioxidant properties. The total phenolic content and radical scavenging activities of Jerusalem artichoke leaves were investigated by Yuan et al. (2012). The authors showed that the leaves of Jerusalem artichoke might be a potential source of natural antioxidants.

Another group of secondary metabolites identified in the leaves were sesquiterpene lactones. The ultrahigh performance liquid chromatography coupled with the quadrupole time-of-flight mass spectrometry (UHPLC-Q-TOF-MS method) was used for the simultaneous quantification of eleven sesquiterpene lactones in eleven Jerusalem artichoke leaf samples (Yuan and Yang 2017). The results of the study showed that the contents of lactones in the leaves varied significantly in the Jerusalem artichoke from different areas. Bioassay-directed phytochemical study led to the isolation of a number of sesquiterpene lactone of 3-hydroxy-8 $\beta$-tigloyloxy-1,10-dehydroariglovin, and ten known sesquiterpene lactones (Yuan et al. 2013).

Abou Baker et al. (2010) proved that the sesquiterpene lactones exhibited cytotoxicity against 1031 leukemia and HCT 116 cancer cell lines, while heliangine showed moderate activity against Hep G2 and breast cancer MCF7 cell lines.

Significant amount of phytochemicals was contained also in tubers of Jerusalem artichoke. The ethanol extracts showed antidiabetic effect in streptozotocin induced diabetic rats and it also possessed an inhibitory effect on kidney tissue TBARS levels (Aslan et al. 2010). The hydrodistilled essential oils from fresh tubers of Jerusalem artichoke, characterization by GC-FID, GC/MS, and ${ }^{13} \mathrm{C}-\mathrm{NMR}$ analyses allowed the identification of 195 compounds in total, mainly $\beta$-bisabolene, helianthol $\mathrm{A}$, desmethoxyencecalin, desmethylencecalin, euparin, and dihydroeuparin (Radulovic and Dordevic 2014). Other compounds identified by GC-MS, TLC and HPLC methods, in the tubers of $H$. tuberosus were the coumarins, ayapin and scopoletin (Cabello-Hurtado et al. 1998). Ayapin (6,7-methylenedioxy-coumarin) and scopoletin (6-methoxy-7-hydroxy-coumarin) are phenolic compounds belonging to the family of the simple 7-hydroxylated coumarins. Both compounds were accumulated in response to the treatment with chemical elicitors, for example $\mathrm{CuCl}_{2}$ or sucrose. Phenolics (such as ferulic acids) from the tubers of $H$. tuberosus were separated and identified by Tchone et al. (2006). Using the ultraperformance liquid chromatography-mass spectrometry with an electrospray ionization, Kapusta et al. (2013) characterized phenolic compounds in $H$. tuberosus tubers of two Polish cultivars, Rubik and Albik. Seven compounds, including the naturally occuring isomers of caffeoylquinic acid namely neo-chlorogenic acid, chlorogenic acid and crypto-chlorogenic acid, four isomeric di-caffeoylquinic acids (3,4- $O$-dicaffeoyl; 3,5-O-dicaffeoyl; 1,3-O-dicaffeoyl and 4,5-O-dicaffeoyl esters), were detected. Yuan et al. (2012) investigated total concentration of phenolic acids in the tubers of two Jerusalem artichoke cultivars. The predominant compound in all the samples was 3,4-O-dicaffeoylquinic acid. This compound constituted 38 and $35 \%$ of total phenolic content in Rubik and Albik varieties, respectively. Among the caffeoylquinic acids, the 3-caffeoylquinic acid showed the highest concentration in both cultivars, accounting for $28 \%$ (Rubik) and 25\% (Albik) of the total phenolic content. Phytochemicals identified in Jerusalem artichoke are shown in Table 4. 
Table 4 Phytochemicals identified in Helianthus tuberosus L

\begin{tabular}{|c|c|c|}
\hline $\begin{array}{l}\text { Part of } \\
\text { plants }\end{array}$ & Metabolite & References \\
\hline \multirow[t]{4}{*}{ Tubers } & $\begin{array}{l}\text { Coumarin: ayapin (6,7-methylenedioxy-coumarin), scopoletin (6-methoxy-7-hydroxy- } \\
\text { coumarin) }\end{array}$ & $\begin{array}{l}\text { Cabello-Hurtado et al. } \\
\text { (1998) }\end{array}$ \\
\hline & Ferulic acids & Tchone et al. (2006) \\
\hline & $\begin{array}{l}\text { Isomers of caffeoylquinic acid (neo-chlorogenic acid, chlorogenic acid, crypto-chlorogenic } \\
\text { acid), isomeric di-caffeoylquinic acids }(3,4-O \text {-dicaffeoyl; 3,5- } O \text {-dicaffeoyl; } 1,3-O \text { - } \\
\text { dicaffeoyl; 4,5-O-dicaffeoyl esters) }\end{array}$ & Kapusta et al. (2013) \\
\hline & $\begin{array}{l}\text { Cyclopentanol, hexadecanoic acid, 9-octadecenoic acid, 9-octadecenoic acid, } \\
\text { 9-octadadecinoic acid, octadeconic acid, 13-octadecenal and 9-octadeconic acid, utero- } \\
\text { noenen-1-ol-3; 2-propen-1-ol; 3-deoxy-d-manneolclactone; heyadecanic acid; } \\
\text { 1-pyrrolin,3-ethyl; 9-octadecnoic acid; octadelenoic acid; 13-octa decnal; 1,2-epoxy-1- } \\
\text { vinylcyclode coene and cycloprtadecanon c, 2-hydroxy, 2-furan carboxaldehyde; 2-furan } \\
\text { carboyaldehyde; dodecane1,1-oxybis; glycine,n-methyl-n-1-oxadodecyl; hexa-decaneic } \\
\text { acid; 9-octadecenoic acid; oleic acid; 9-octadecenal; 9-octadecenal and phthalic acid } \\
\text { disooctyl ester }\end{array}$ & $\begin{array}{l}\text { Yaeghoobi-Khanghahi } \\
\text { et al. (2014) }\end{array}$ \\
\hline \multirow[t]{5}{*}{ Leaves } & Flavone glucosides (kaempferol 3-O-glucoside and quercetin 7-O-glucoside) & Chae et al. (2002) \\
\hline & Chlorogenic acids (feruloylquinic acid, caffeoylquinic acids, dicaffeoylquinic acids) & Yuan et al. (2008) \\
\hline & $\begin{array}{l}\text { Phenolic compounds (caffeic acid, 3- } O \text {-caffeoylquinic acid, 3,5-dicaffeoylquinic acid, 1,5- } \\
\text { dicaffeoylquinic acid, 4,5-dicaffeoylquinic acid, 3,5-dicaffeoylquinic acid methyl ether) }\end{array}$ & Yuan et al. (2012) \\
\hline & $\begin{array}{l}\text { Chlorogenic acids (two isomers of caffeoylquinic acid, 3- } O \text {-caffeoylquinic acid, caffeic } \\
\text { acid, } p \text {-coumaroyl-quinic acid, 3,4-dicaffeoyquinic acid, feruloylquinic acid, 3,5- } \\
\text { dicaffeoylquinic acid, 1,5-dicaffeoylquinic acid and 4,5-dicaffeoylquinic acid) and other } \\
\text { phenolics (isorhamnetin glucoside, caffeoyl glucopyranose, kaempferol glucuronide, } \\
\text { kaempferol-3- } O \text {-glucoside) }\end{array}$ & Chen et al. (2014) \\
\hline & $\begin{array}{l}\text { Sesquiterpene lactones (3-hydroxy-8 } \beta \text {-tigloyloxy-1,10-dehydroariglovin; 4,15-iso- } \\
\text { atripliciolide methylacrylate; } 4,15 \text {-iso-atripliciolide tiglate; } 4,15 \text {-iso-atripliciolide } \\
\text { isobutyrate; 4,15-iso-atripliciolide angelate, budlein A methylacrylate; budlein A tiglate, } \\
\text { desacetylovatifolin, 1a-hydroxypinnatifidin, 1a-acetoxypinnatifidin; melampolide) and } \\
\text { flavones (pedunculin; 5,8-diOH-6,7diMeO-2-(3,4-diMeOPh)-4-benzopyrone) }\end{array}$ & $\begin{array}{l}\text { Yuan et al. (2013) and } \\
\text { Yuan and Yang (2017) }\end{array}$ \\
\hline Callus & Lectins & Nakagawa et al. (1996) \\
\hline Flowers & $\begin{array}{l}\text { Terpenoids:monoterpenoid (loliolide acetate), kauranediterpenoids(ent-kaur-16-en-19-oic } \\
\text { acid,15-hydroxykaur-16-en-19-oic acid, 17-hydroxykaur-15-en-19-oic acid, 15 } \alpha \text { - } \\
\text { tiglinoyloxykaur-16-en-19-oic acid)and triterpenoids (faradiol 3-O-fatty acid ester } \\
\text { derivative); coumarins ( } 8 \text {-methoxyobliquin, 7-O-prenylscopoletin);flavonoids } \\
\text { (isoliquiritigenin } 2,4,2^{\prime}, 4^{\prime} \text {-tetrahydroxychalcone, liquiritigenin, acerosin, quercetin 7-O- } \\
\beta \text {-glucoside, sulfuretin, sulfurein glycoside) andchromone derivative (7- } \\
\text { hydroxychromone) }\end{array}$ & Jantaharn et al. (2018) \\
\hline $\begin{array}{l}\text { Whole } \\
\text { plants }\end{array}$ & $\begin{array}{l}\text { Ent-17-oxokaur-15(16)-en-19-oic acid; ent-17-hydroxykaur-15(16)-en-19-oic acid; ent- } \\
\text { 15bhydroxykaur-16(17)-en-19-oic acid methyl ester; ent-15-nor-14-oxolabda-8(17); 12E- } \\
\text { dien-18-oic acid; 4,15-isoatriplicolide angelate; 4,15-isoatriplicolide methylacrylate; }(+) \text { - } \\
\text { pinoresinol; (-)-loliolide; vanillin }\end{array}$ & Pan et al. (2009) \\
\hline
\end{tabular}

\section{Giant Miscanthus (Miscanthus giganteus)}

Giant Miscanthus (Miscanthus $\times$ giganteus) is a perennial, warm-season $\mathrm{C} 4$ grass (Fig. 2). Giant Miscanthus (Miscanthus $\times$ giganteus) is a perennial, warm-season $\mathrm{C} 4$ grass. This is a naturally occurring hybrid between diploid Miscanthussinensis and tetraploid M. sacchariflorus (Brosse et al. 2012). A characteristic feature of these plants is the very efficient photosynthesis process, which ensures a large increase in biomass from the assimilation surface. Miscanthus is a major bioenergy crop in Europe and a potential feedstock for second generation biofuels (Zhu et al. 2015). Its use for energy production has the potential to provide significant fossil energy substitution (Heaton et al. 2008) and greenhouse gas mitigation (Clifton-Brown et al. 2007). The Miscanthus biomass can be used as a replacement for lignite, a raw 
material for the production of fuel gas and ethanol. The energy value of Miscanthusis comparable to the value of hardwoods (approx. $19 \mathrm{MJ} / \mathrm{kg}$ ); (Sacała 2011). The studies of Parveen et al. (2011) have been the first report of the hydroxycinnamic acid profile of leaves and stems of $M$. giganteus, wherein more than twenty hydroxycinnamates were identified by UV and LC-ESI-MS ${ }^{\mathrm{n}}$ (Table 5). Comparative LC-MS studies on the leaf extract showed the presence of isomers of $O$-caffeoylquinic acid (3-CQA, 4-CQA and 5-CQA), $O$-feruloylquinic acid (3-FQA, 4-FQA and 5-FQA) and para-coumaroylquinic acid (3-pCoQA and 5 - $p$ CoQA). The presence of certain classes of hydroxycinnamic esters in $M$. giganteus tissues is very important, in the case of potential application of this plant as a feedstock for platform chemicals and biological conversion to biofuels.

The hexaploid Miscanthus $\times$ giganteus can be induced from triploid $M \times$ giganteus. Induced polyploidy can influence the concentration of secondary metabolites (Kato and Birchler 2006; Omidbaigi et al. 2010). The pyrogallol, catechin, veratric acid, $o$ coumaric acid and myricetin were present at higher concentrations in leaf extracts of hexaploid compared to triploid plants (Ghimire et al. 2016). On the contrary, ferulic acid, gentisic acid, veratric acid, rutin, hesperidin, and myricetin were present in significantly higher levels in triploid plants. Villaverde et al. (2009) studied the chemical composition of Miscanthus $x$ giganteus extractives using gas chromatography-mass spectrometry (GC-MS). The lipophilic extracts of bark and core of the Miscanthus $x$ giganteus stalk contained sterols and fatty acids. The concentration of aromatic compounds was $521 \mathrm{mg} / \mathrm{kg}$ of bark, with vanillin, vanillic acid and $p$-hydroxybenzaldehyde as the major constituents. Sterols constituted about $949 \mathrm{mg} / \mathrm{kg}$ of dry core with stigmasterol, campesterol, $\beta$-sitosterol and 7-oxo- $\beta$ sitosterol, as the major compounds. The high concentration of valuable compounds in core and bark of $M . \times$ giganteus, which constitute waste in most applications, give an opportunity for the integrated upgrading of this grass within the bio-refinery perspective. The analysis of secondary plant metabolites in Miscanthus $\times$ giganteus root exudates showed the presence of various polyphenolics, some of which may take part in biostimulation processes (Techer et al. 2011). It was confirmed also by the study of Techer

Table 5 Phytochemicals identified in Miscanthus gigantheus

\begin{tabular}{|c|c|c|}
\hline $\begin{array}{l}\text { Part of } \\
\text { plants }\end{array}$ & Metabolite & References \\
\hline \multirow[t]{2}{*}{ Leaves } & $\begin{array}{l}\text { Hydroxycinnamic acid (isomers of: } O \text {-caffeoylquinic acid (3- } O \text {-caffeoylquinic acid, } \\
\text { 4- } O \text {-caffeoylquinic acid, 5- } O \text {-caffeoylquinic acid), } O \text {-feruloylquinic acid (3-O- } \\
\text { feruloylquinic acid, 4- } O \text {-feruloylquinic acid and 5- } O \text {-feruloylquinic acid) and para- } \\
\text { coumaroylquinic acid (3-para-coumaroylquinic acid and 5-para-coumaroylquinic } \\
\text { acid) }\end{array}$ & Parveen et al. (2011) \\
\hline & $\begin{array}{l}\text { Chlorogenic, ferulic, veratric, } o \text {-coumaric, gentisic acids, pyrogallol, catechin, } \\
\text { myricetin, rutin, hesperidin }\end{array}$ & Ghimire et al. (2016) \\
\hline \multirow[t]{2}{*}{ Stems } & $\begin{array}{l}\text { Hydroxycinnamic acid (isomers of: } O \text {-caffeoylquinic acid (3-O-caffeoylquinic acid, } \\
\text { 4- } O \text {-caffeoylquinic acid, 5- } O \text {-caffeoylquinic acid), } O \text {-feruloylquinic acid (3-O- } \\
\text { feruloylquinic acid, 4- } O \text {-feruloylquinic acid and 5-O-feruloylquinic acid) and } \\
\text { 5-para-coumaroylquinic acid) }\end{array}$ & Parveen et al. (2011) \\
\hline & Chlorogenic and gentisic acid, pyrogallol, catechin & Ghimire et al. (2016) \\
\hline Roots & $\begin{array}{l}\text { Quercetin, rutin, isovitexin, catechin, apigenin, caffeic, chlorogenic, } p \text {-coumaric, } \\
\text { cinnamic and gallic acid }\end{array}$ & $\begin{array}{l}\text { Techer et al. (2011), Techer } \\
\text { et al. (2012) }\end{array}$ \\
\hline Barks & $\begin{array}{l}\text { Vanillin, vanillic acid, } p \text {-hydroxybenzaldehyde, sterols (stigmasterol, campesterol, } \beta \text { - } \\
\text { sitosterol, 7-oxo- } \beta \text {-sitosterol) }\end{array}$ & $\begin{array}{l}\text { Villaverde et al. (2009) and } \\
\text { Villaverde et al. (2010) }\end{array}$ \\
\hline Bio-oils & $\begin{array}{l}\text { Phenol (2-methoxy-4-methylphenol, 1,2-benzenediol, 3-methoxy-1,2-benzenediol, } \\
\text { 4-ethyl-2-methoxy-phenol, 2-methoxy-4-vinylphenol, 2,6-dimethoxy-phenol, } \\
\text { 2-methoxy-6-(2-propenyl)-phenol, 4-(3-hydroxy-1-propenyl)-2-methoxy-phenol, } \\
\text { 2,6-dimethoxy-4-(2-propenyl)-phenol) and phenols (4-ethylphenol, 2/3- } \\
\text { methylphenol, 4-methylphenol, 2-methoxy-phenol) }\end{array}$ & Greenhalf et al. (2013) \\
\hline
\end{tabular}


et al. (2012). Secondary root metabolites could be involved in the biostimulation of PAH-utilizing soil bacteria. It was shown that the addition of root exudate promoted bacterial growth and the catabolic activity of polycyclic molecules.

\section{Reed canary grass (Phalaris arundinacea L.)}

Reed canary grass (RCG) is perennial grass, belonging to the Poaceae family (Fig. 2). Thanks to the high yield per hectare, it may be cultivated as energy crops for combustion or biogas and bioethanol production (Oleszek et al. 2014). Phytochemicals of RCG are mainly alkaloids, either nitrogen-based or steroidal in nature (Lyman et al. 2012). Two major classes of alkaloids include gramine [1-(1H-indol-3-yl)- $N, N$ dimethylmethanamine] and tryptamine derivatives (Marten et al. 1973, 1981). Plant genotypes of $P$. arundinacea can be classified into three phenotypic groups based on the type of alkaloids present. The $\mathrm{MeO}$ phenotype contains the methoxy derivatives of the tryptamines (5-methoxy- $N$-methyltryptamine, 5 -methoxy- $N, N$-dimethyltryptamine) and $\beta$-carbolines (2-methyl-6-methoxy-1,2,3,4-tetrahydro $\beta$-carboline). The $\mathrm{T}$ phenotype contains the non-methoxy derivatives of the tryptamines ( $N$-methyltryptamine; $N$,Ndimethyltryptamine) and $\beta$-carbolines (2-methyl$1,2, \sim, 4 \sim$ tetrahydro- $\beta$-carboline). The third phenotype, $\mathrm{G}$, contains gramine and is recessive to the other two phenotypes. Most of the recently developed cultivars of RCG are of the G phenotype, and also contain hordenine. Hordenine is the only alkaloid detected in RCG, which is not an indole in the structure. Determination of hordenine and gramine in $P$. arundinaceae material was reported by e.g. Coulman et al. (1977), Woods et al. (1979), Majak et al. (1979) and Duynisveld et al. (1990) (Table 6). Grzelak et al. (2018) identifed six alkaloids, i.e. tryptophol and gramine (indole alkaloids), as well as lupanine and 13-OH lupanine and lupanine esters- $13 \alpha$-isovalericlupanine and 13 $\alpha$-tigloyloxylupanine (quinolysidine alkaloids). The authors stated that the concentrations of the compounds depended on the stage of plants maturity, while dominant alkaloids in the growth stage were gramine and lupanine. Alkaloids in RCG are confined largely in the leaf blades, than in the culm, therefore, it decreased in whole plant with a maturity, due to increasing culm/foliage ratio (Otani et al. 1997; Gołębiowska et al. 2017). Their concentration is enhanced by moisture stress, light intensity and high rates of $\mathrm{N}$ fertilizer, especially in the $\mathrm{NH}_{4}-\mathrm{N}$ form (Frelich and Marten 1972; Grzelak et al. 2018). Cutting of RCG every second week produced a sharp increase in indole alkaloid levels, as compared with levels in free growth tissue (Woods and Clark 1971). Alkaloid concentration is greatly reduced in dried grass (Donker et al. 1976) and in silage (Hovin et al. 1980). Alkaloids are secondary metabolites with diverse biological activities (Steppuhn et al. 2004). Their bioactive properties make alkaloids important players in plant defense responses against insects, microbes, and other herbivores (Grzelak et al. 2018). Alkaloids in $P$. arundinacea negatively influence on grass palatability and sometimes have undesirable effects on ruminant animals (Hovin and Marten 1975; Popp et al. 2016). Thus, the differences in palatability

Table 6 Phytochemicals identified in Phalaris arundinacea $\mathrm{L}$

\begin{tabular}{|c|c|c|}
\hline $\begin{array}{l}\text { Part of } \\
\text { plant }\end{array}$ & Metabolite & References \\
\hline \multirow[t]{4}{*}{$\begin{array}{c}\text { Aerial } \\
\text { part }\end{array}$} & Hordenine, gramine & $\begin{array}{l}\text { Coulman et al. (1977), Woods et al. (1979), Majak } \\
\text { et al. (1979) and Duynisveld et al. (1990) }\end{array}$ \\
\hline & $\begin{array}{l}\text { Tryptophol, gramie, lupanine and } 13-\mathrm{OH} \text { lu panine, lupanine esters- } \\
\text { 13a-isovalericlupanine, 13a-tigloyloxylupanine }\end{array}$ & Grzelak et al. (2018) \\
\hline & Gramine, ergovaline, condensed tannins, saponins & Lyman et al. (2012) \\
\hline & $\begin{array}{l}\text { Gramine, 5-methoxy-N-methyltryptamine, 5-methoxy-N,N- } \\
\text { dimethyltryptamine) and } \beta \text {-carbolines (2-methyl-6-methoxy- } \\
\text { 1,2,3,4-tetrahydro } \beta \text {-carboline, N-methyltryptamine; } \\
\text { N,Ndimethyltryptamine, 2-methyl-1,2, ,4 tetrahydro- } \beta \text { - } \\
\text { carboline }\end{array}$ & Marten et al. (1973) and Marten et al. (1981) \\
\hline
\end{tabular}



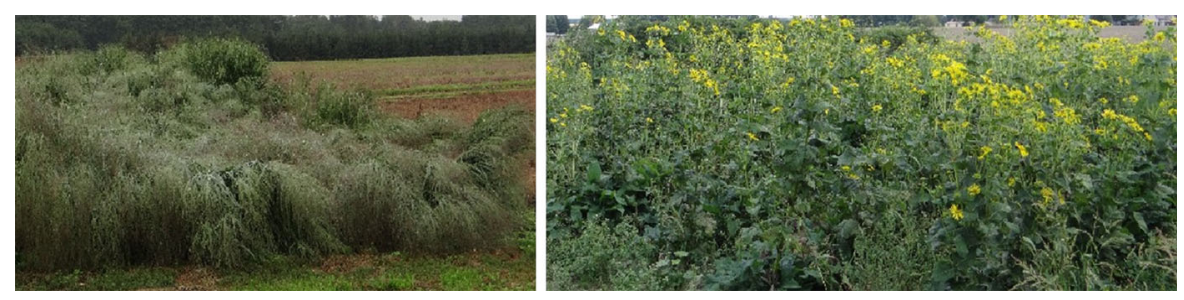

Fig. 3 Panicum virgatum and Sylphium perfoliatum

and alkaloid concentration between $P$. arundinaceae genotypes have a substantial biological significance for grazing steers and lambs (Marten et al. 1976). Alkaloids of RCG are known to have wide biocidal activity. Lovett et al. (1994) stated that hordenine inhibits seedling growth of white mustard, Sinapis alba, Mythimna convecta and Dreschslera teres. Golebiowska et al. (2017) investigated the influence of aqueous extract of reed canary grass leaves and runners on the growth of selected weed such as Geranium pusillum L., Amaranthus retroflexus L., Papaver rhoeas L., Viola arvensis Murray and Stellaria media (L.) Vill. The authors proved that inhibition depended on the collection period and habitat of the plants. The strongest effect was observed for the extract from the biomass collected in autumn before the winter dormancy. Gramine, an indolic alkaloid, apart from being phytotoxic, it was proven to have antibacterial properties against Pseudomonas (Sepulveda and Corcuera 1990). Furthermore, gramine inhibits the growth of Drechslera teres, armyworm, Mythimna convecta and disruptsthe respiratory chain at complex I in rat liver mitochondria and in bovine heart submitochondrial particles (Andreo et al. 1984). Moreover, this compound behaved as a typical uncoupler of photosynthetic phosphorylation in spinach thylakoids. Recent study on the action of gramine from reed canary grass showed its negative influence on the methane fermentation process (Popp et al. 2016). It was stated, that its presence in biomass of reed canary grass caused increase in methane yield. Simultaneously, it has been proven that microorganisms were able to adaptate to such unfavorable conditions and to become resistant to this substance.

\section{Switchgrass (Panicum virgatum L.)}

Panicum virgatum L. (switchgrass) is a dominant, native, perennial species found in the tall grass prairie, which can be efficient and environmentally friendly energy crop (Shui et al. 2010); (Fig. 3). Switchgrass could be used as livestock feed, if it was not for the presence of steroidal saponins that has been reported as the reason for hepatogenous photosensitization in sheep, lambs and horses. Saponins, with diosgenin as the main aglycon moiety, were identified in leaves and stems, wherein the leaves have higher concertation than the stems (Lee et al. 2001). Lee et al. (2009) identified three major saponins (saponin A-C) from four switchgrass cultivars (Table 7). Saponin A was dichotomin [(25R)-furost-5-ene-3 $\beta, 22 \alpha, 26$-triol 3-O$\alpha$-L-rhamnopyranosyl-( $\rightarrow 4$ )- $\alpha$-L-rhamnopyranosyl$(1 \rightarrow 4)$-[ $\alpha$-L-rhamnopyranosyl-( $1 \rightarrow 2)]-\beta$-D-glucopyranosyl 26-O- $\beta$-D-glucopyranoside], saponin B was (25R)-furost-5-ene-3 $\beta, 22 \alpha, 26$-triol 3 -O- $\alpha$-Lrhamnopyranosyl-( $1 \rightarrow 2)-\beta$-D-glucopyranosyl 26- $O$ $\beta$-D-glucopyranoside and saponin $\mathrm{C}$ was protodioscin (25R)-furost-5-ene-3 $\beta, 22 \alpha, 26$-triol 3- $O-\alpha$-Lrhamnopyranosyl-( $1 \rightarrow 4)$-[ $\alpha$-L-rhamnopyranosyl$(1 \rightarrow 2)]-\beta$-D-glucopyranosyl $\quad 26-O-\beta$-D-glucopyranoside. The concentration of individual and total saponins differed among cultivars and parts of plant.

Sarath et al. (2007) studied the internode structure and cell wall composition in maturing tillers of switch grass and showed the presence of soluble phenolics. The concentration and complexity of soluble phenolics analyzed by HPLC decreased with increasing distance of the internodes from the top of the plant. Soluble phenolics concertation and complexity was highest in top internodes. The lower internodes contained higher content of wall-bound phenolic acids, principally as 4-coumarate and ferulate. The results of analyses showed that the soluble fractions obtained from top internodes contained substantial amounts of caffeic, 4-coumaric and ferulic acids, and relatively lower amounts of protocatechuic, syringic, sinapic and vanillic acids. Low temperature alkaline hydrolysis of internode samples predominantly 
Table 7 Phytochemicals identified in Panicum virgatum L

\begin{tabular}{|c|c|c|}
\hline $\begin{array}{l}\text { Part of } \\
\text { plants }\end{array}$ & Metabolites & References \\
\hline \multirow{3}{*}{$\begin{array}{r}\text { Aerial } \\
\text { parts }\end{array}$} & Saponins (diosgenin and yamogenin) & Lee et al. (2001) \\
\hline & Monoterpenes & $\begin{array}{l}\text { Eller et al. } \\
\text { (2011) }\end{array}$ \\
\hline & Rutin, quercitrin & $\begin{array}{l}\text { Nirmal et al. } \\
\quad(2009)\end{array}$ \\
\hline \multirow[t]{3}{*}{ Leaves } & 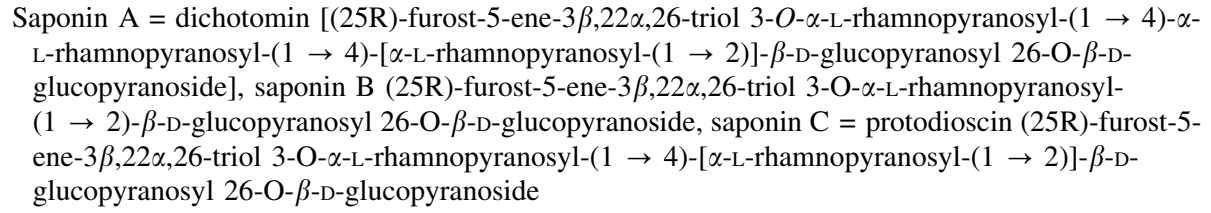 & Lee et al. (2009) \\
\hline & Trigonelline (alkaloid) & $\begin{array}{l}\text { Schwartz et al. } \\
\text { (2014) }\end{array}$ \\
\hline & Flavonoid quercetin & $\begin{array}{l}\text { Martin et al. } \\
\text { (2011) }\end{array}$ \\
\hline Shoots & Alkaloids, phenols, organic acids & $\begin{array}{l}\text { Shui et al. } \\
\text { (2010) }\end{array}$ \\
\hline \multirow[t]{3}{*}{ Stems } & Saponin A, B and C & Lee et al. (2009) \\
\hline & Flavonoid quercetin & $\begin{array}{l}\text { Martin et al. } \\
\text { (2011) }\end{array}$ \\
\hline & Sterols (cholesterol, campesterol, ergosta-5,7,2, 2-trien-3-ol, stigmasterol, $\beta$-sitosterol & Yan et al. (2010) \\
\hline Cell wall & $\begin{array}{l}\text { Soluble phenolics (caffeic, 4-coumaric, ferulic acids, protocatechuic, syringic, sinapic and vanillic } \\
\text { acids, ricin) }\end{array}$ & $\begin{array}{l}\text { Sarath et al. } \\
\text { (2007) }\end{array}$ \\
\hline
\end{tabular}

released caffeic, 4-coumaric and ferulic acid. Schwartz et al. (2014) reported the biosynthesis and accumulation of alkaloids trigonelline in leaves of $P$. virgatum caused by water-deficit stress. Nonetheless, plant response varied for different cultivars. Trigonelline concentration ranged from 0.5 to $31.8 \mathrm{mg} / \mathrm{g}$ of fresh weight depending of the cultivar.

\section{Cup plant (Silphium perfoliatum)}

Cup plant (Silphium perfoliatum L.) is a tall, perennial plant from Asteraceae family, native to North America (El-Sayed et al. 2002); (Fig. 3). It is regarded as suitable feedstock for bioenergy production, due to its low maintenance requirements, high biomass yield and efficient methane production in anaerobic digestion process (Gansberger et al. 2015). Nonetheless, many studies were performed on the bioactive compounds included in S. perfoliatum, and showed that this plant is rich in phenolic acids, flavonoids, terpenes, saponins, as well as essential oils (El-Sayed et al. 2002; Kowalski and Wolski 2003, 2005; Kowalski 2005; Kowalski and Kędzia 2007). Kowalski (2005) stated that lipophilic extracts of leaves and inflorescence is similar in composition, while the composition of rhizome extract significantly differed from them. Kowalski and Wolski (2005) studied the content and chemical composition of essential oil of leaves, inflorescences and rhizomes of $S$. perfoliatum L. The highest content of oil was contained in rhizomes $(0.41 \% \mathrm{v} / \mathrm{w})$, with the tricyclic sesquiterpenes 7- $\beta$-H-silphiperfol-5-ene, isocomene, modhephene and $7-\alpha-\mathrm{H}$-silphiperfol-5-ene as dominating compounds, which were not detected in leaves and inflorescences. These authors, in their other work on bioactive compounds in $S$. perfoliatum $\mathrm{L}$. identified seven phenolic acids and found that caffeic acid was the most predominant compound in this plant (from $67.8 \%$ of total in the leaves to $94.4 \%$ in the rhizomes) (Kowalski and Wolski 2003). El-Sayed et al. (2002) isolated two new kaempferol derivatives and other nine known flavonoids from the leaves of $S$. 
Table 8 Phytochemicals identified in Silphium perforiatum

\begin{tabular}{|c|c|c|}
\hline Part of plants & Metabolite & References \\
\hline \multirow[t]{7}{*}{ Leaves } & $\alpha$-amyrine, $\beta$-amyrine, heptacosane, sigma sterol, $\gamma$-sitosterol & Kowalski (2005) \\
\hline & $ß$-caryophyllene, caryophyllene oxide, germacrene D, $\alpha$-pinene & \\
\hline & $\begin{array}{l}\text { Kaempferol 3-O-B-D-apiofuranoside } 7-O-\alpha-\mathrm{L}-\text { rhamnosyl- }\left(1^{\prime \prime \prime \prime} \rightarrow 6^{\prime \prime \prime}\right)-\mathrm{O}-\beta-\mathrm{D}- \\
\text { galactopyranoside, }\end{array}$ & $\begin{array}{l}\text { El-Sayed et al. } \\
\text { (2002) }\end{array}$ \\
\hline & $\begin{array}{l}\text { kaempferol 3-O- } \beta \text {-D-apiofuranoside } 7-\mathrm{O}-\alpha-\mathrm{L}-\mathrm{rhamnosyl}-\left(1^{\prime \prime \prime \prime} \rightarrow 6^{\prime \prime \prime}\right)-\mathrm{O}-\beta-\mathrm{D}-\left(2^{\prime \prime \prime}-O-E-\right. \\
\text { caffeoylgalactopyranoside) }\end{array}$ & \\
\hline & $\begin{array}{l}\text { Tricyclene, } \alpha \text {-pinene, camphene, sabinene, } \beta \text {-pinene, limonene, } \alpha \text {-pinene oxide, } \\
\text { a-campholenal, trans-pinocarveol, trans-verbenol, pinocarvone, myrtenal, myrtenol, } \\
\text { verbenone, }\end{array}$ & $\begin{array}{l}\text { Kowalski and } \\
\text { Kędzia (2007) }\end{array}$ \\
\hline & $\begin{array}{l}\alpha \text {-copaene, }, \text {-bourbonene, } \alpha \text {-isocomene, } \beta \text {-caryophyllene, } \beta \text {-Copaene, trans- } \alpha \text {-bergamotene, } \alpha \text { - } \\
\text { humulene, germacrene } D \text {, cubebol, spathulenol, caryophyllene oxide, humulene epoxide II, } \\
\beta \text {-oplopenone, epoxy allo-alloaromadendrene, khusinol, } 6,10,14 \text {-trimethyl-2- } \\
\text { pentadecanone, hexadecanoic acid, cis-phytol, }(\mathrm{Z}, \mathrm{Z}, \mathrm{Z})-9,12,15 \text {-octadecatrienoic acid } \\
\text { methyl ester, pentacosane, docosanoic acid methyl ester, heptacosane, tetracosanic acid } \\
\text { methyl ester, octacosane, squalene, nonacosane, hexacosanoic acid methyl ester, } \\
\text { hentriacontane, octadecanoic acid methyl ester, vitamin E, stigmasterol, } \gamma \text {-sitosterol, } \beta \text { - } \\
\text { amyrine, } \alpha \text {-amyrine }\end{array}$ & \\
\hline & Caffeic acid, $p$-coumaric acid, proto-catechuic acid, vanilic acid, chlorogenic acid & $\begin{array}{l}\text { Kowalski and } \\
\text { Wolski (2003) }\end{array}$ \\
\hline \multirow[t]{4}{*}{ Inflorescences } & $\begin{array}{l}\alpha \text {-amyrine, } \beta \text {-amyrine, heptacosane, sigma sterol, } \gamma \text {-sitosterol, } \beta \text {-caryophyllene, } \\
\text { caryophyllene oxide, germacrene } \mathrm{D}, \alpha \text {-pinene }\end{array}$ & Kowalski (2005) \\
\hline & $\begin{array}{l}\text { Tricyclene, } \alpha \text {-pinene, camphene, sabinene, } \beta \text {-pinene, limonene, } \alpha \text {-pinene oxide, } \alpha \text { - } \\
\text { campholenal, trans-pinocarveol, trans-verbenol, pinocarvone, myrtenal, myrtenol, } \\
\text { verbenone, }\end{array}$ & $\begin{array}{l}\text { Kowalski and } \\
\text { Kędzia (2007) }\end{array}$ \\
\hline & $\begin{array}{l}\alpha \text {-copaene, }, \text {-bourbonene, }, \beta \text {-caryophyllene, trans- } \alpha \text {-bergamotene, } \alpha \text {-humulene, Germacrene } \\
\mathrm{D}, \gamma \text {-cadinene, cubebol, myristicin, }(\mathrm{E}) \text {-nerolidol, spathulenol, caryophyllene oxide, } \\
\text { humulene epoxide II, } \beta \text {-oplopenone, epoxy allo-alloaromadendrene, khusinol, oplopanone, } \\
\text { 6,10,14-trimethyl-2-pentadecanone, hexadecanoic acid, cis-phytol, }(\mathrm{Z}, \mathrm{Z}, \mathrm{Z})-9,12,15 \text { - } \\
\text { Octadecatrienoic acid methyl ester, pentacosane, docosanoic acid methyl ester, } \\
\text { heptacosane, tetracosanic acid methyl ester, octacosane, squalene, nonacosane, } \\
\text { hexacosanoic acid methyl ester, hentriacontane, octadecanoic acid methyl ester, vitamin E, } \\
\text { stigmasterol, } \gamma \text {-sitosterol, } \beta \text {-amyrine, } \alpha \text {-amyrine }\end{array}$ & \\
\hline & $\begin{array}{l}\text { Caffeic acid, ferulic acid, } p \text {-coumaric acid, proto-catechuic, } p \text {-hydroxybenzoic acid, vanilic } \\
\text { acid }\end{array}$ & $\begin{array}{l}\text { Kowalski and } \\
\text { Wolski (2003) }\end{array}$ \\
\hline \multirow[t]{3}{*}{ Rhizomes } & $\begin{array}{l}\text { 16-acetocarterochaetol, 7- } \beta \text {-H-silphiperfol-5-ene, } 7-\alpha \text {-H-silphiperfol-5-ene, } \delta \text {-elemene, } \\
\text { isocomene, germacrene } \mathrm{D} \text {, modhephene }\end{array}$ & Kowalski (2005) \\
\hline & $\begin{array}{l}\text { 7- } \alpha \text {-H-silphiperfol-5-ene, } \delta \text {-elemene, } 7-\beta \text {-H-silphiperfol-5-ene, } \alpha \text {-longipinene, silphiperfola- } \\
\text { 5,7(14)-diene, silphiperfol-6-ene, modhephene, } \beta \text {-elemene, } \beta \text {-isocomene, } \alpha \text {-humulene, } \\
\text { Germacrene D, } \beta \text {-bisabolene, cubebol, myristicin, spathulenol, caryophyllene oxide, } \\
\text { presilphiperfolan- } 8 \text {-ol, humulene epoxide II, } \beta \text {-oplopenone, oplopanone, ambroxide, } \\
\text { 16-acetoxycarterochaetol, stigmasterol, } \gamma \text {-sitosterol, } \beta \text {-amyrine, } \alpha \text {-amyrine }\end{array}$ & $\begin{array}{l}\text { Kowalski and } \\
\text { Kędzia (2007) }\end{array}$ \\
\hline & Caffeic acid, ferulic acid, $p$-coumaric acid, proto-catechuic, $p$-hydroxybenzoic acid & $\begin{array}{l}\text { Kowalski and } \\
\text { Wolski (2003) }\end{array}$ \\
\hline
\end{tabular}

perfoliatum $\mathrm{L}$. The phytochemicals identified in cup plant was listed in Table 8.

Kowalski and Kędzia (2007) mentioned that the root of S. perfoliatum exhibit antiemetic, antirheumatic, analgesic, tonic and diaphoretic activities.
Moreover, it was helpful in liver diseases, spleen maladies, internal bruises, ulcers, as well as fever and debility. Syrov et al. (1992) studied anticholesterolemic effect of saponins isolated from S. perfoliatum leaves and found that concentration of cholesterol 

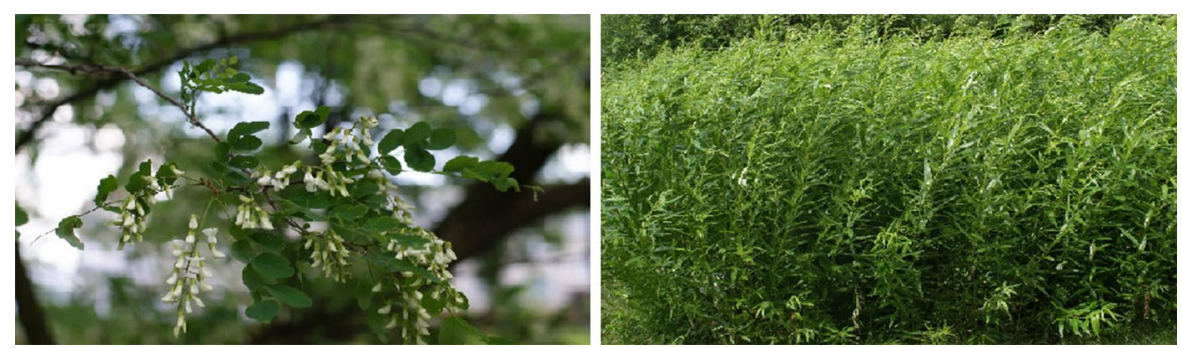

Fig. 4 Robinia preudoacacia and Salix sp

in rat blood decreased by $12 \%$ and $19 \%$ depending on a dose and time.

Phytochemicals of cup plant exhibited also antimicrobial activity. Kowalski and Kędzia (2007) demonstrated significant antibacterial activity of hexane and methanol extract from leaves, inflorescences and rhizomes of cup plant toward Staphylococcus aureus FDA 209P strains. The highest activity was exhibited by alcoholic extracts from $S$. perfoliatum rhizomes compared to extracts from leaves and inflorescences. Davidjanc et al. (1997) found that saponins isolated from cup plant leaves inhibited the development of phytopathogenic fungi such as Drechslera graminea Rabh, Rhizopus nodosus Namysl, and Rhizopus nigricans Ehr. Antifungal activity was confirmed also by Zabka et al. (2011), who tested the influence of crude extract of $S$. perfoliatum leaves on the mycelial growth of Fusarium oxysporum, Fusarium verticillioides,
Penicillium expansum, Penicillium brevicompactum, Aspergillus flavus and Aspergillus fumigatus.

\section{Woody energy crops}

\section{Willow (Salix viminalis L.)}

Willow (Salix viminalis) is of great interest in European countries as energy crop (Fig. 4). This can be cultivated in set-aside fields. The chain for the production of willow stems has the lowest energy input but willow chips are expensive, because of drying costs. On the other hand, they contain high amounts of fiber, polysaccharides and lignin, as well as some extractables that include interesting phytochemicals showing biological activity (Dou et al. 2016); (Table 9). In the bark of S. viminalis, the main

Table 9 Phytochemicals identified in Salix viminalis L

\begin{tabular}{|c|c|c|}
\hline $\begin{array}{l}\text { Part of } \\
\text { plants }\end{array}$ & Metabolites & References \\
\hline \multirow[t]{5}{*}{ Barks } & Salicin (2-hydroxymethyl-phenyl- $\beta$-D-glucopyranoside) & Highfield and Kemper (1999) \\
\hline & $\begin{array}{l}\text { Salicylate compounds (saligenin, salicylic acid, isosalicin, salidroside, picein, } \\
\text { triandrin, salicoylsalicin, salicortin, isosalipurpuroside, salipurpurosid) }\end{array}$ & Kammerer et al. (2005) \\
\hline & Triandrin, salicortin, vimatin, salicin & Palo (1984) \\
\hline & $\begin{array}{l}\text { Polyphenolic compounds (flavonoids, catechin, amelopsin, taxifolin, 7-O- } \\
\text { methyltaxifolin-3'-O-glucoside, 7-O-methyltaxifolin) }\end{array}$ & Shara and Stohs (2015) \\
\hline & $\begin{array}{l}\text { Phenolic acids (salicylic, vanillic, } p \text {-hydroxybenzoic, } p \text {-coumaric, ferulic, caffeic, } \\
\text { syringic) }\end{array}$ & $\begin{array}{l}\text { Skrigan and Vinokurov (1970) and } \\
\text { Pobłocka-Olech et al. (2010) }\end{array}$ \\
\hline \multirow[t]{2}{*}{ Leaves } & $\begin{array}{l}\text { Flavonoids (isorhamnetin 3-O-6-acetylglucoside, isoquercitrin, apigenin 7-O- } \\
\text { glucoside, isorhamnetin 3-O-glucoside) }\end{array}$ & Karl et al. (1977) \\
\hline & Abscisic acid & Alvim (1978) \\
\hline $\begin{array}{r}\text { Aerial } \\
\text { parts }\end{array}$ & $\begin{array}{l}\text { Monoterpens and sesquiterpenes ( } \beta \text {-caryophyllene, } \alpha \text {-farnesene, } \\
(E) \text {-nerolidol, }(E) \text {-4,8-dimethyl-1,3,7-nonatriene, }(E) \text { - } \beta \text {-ocimene)Phenol }\end{array}$ & $\begin{array}{l}\text { Fernandez et al. (2007) } \\
\text { Ucisik and Trapp (2006) }\end{array}$ \\
\hline
\end{tabular}


substances are salicin, triandrin, salicortin and vimatin. Leaves generally show lower phenolic concentration and less glycoside diversity than bark. $S$. viminalis do not have any phenolic glycosides in the leaves. Leaves of $S$. viminalis contain flavonoids: isorhamnetin 3-O-6-acetylglucoside, isoquercitrin, apigenin 7- $\mathrm{O}$-glucoside and isorhamnetin 3-O-glucoside (Karl et al. 1977). The bark of this plant contain several phenolic acids including salicylic, vanillic, $p$-hydroxybenzoic, $p$-coumaric, ferulic, caffeic and syringic (Skrigan and Vinokurov 1970; Pobłocka-Olech et al. 2010). Palo (1984) gives a summary of phenolic glycosides in the bark and leaves of different Salix species.

Willow bark contains active substances known for anti-inflammatory properties. It has been used for over 2000 years in different areas of the world to treat pain and fever e.g. joint, knee or back pain, osteoarthritis, headache, menstrual cramps, tendonitis and flu symptoms (Highfield and Kemper 1999). Therapeutic effectiveness is associated with salicin (2-(hydroxymethyl) phenyl- $\beta$-D-glucopyranoside), which is chemotaxonomic markers of the genus Salix (Pobłocka-Olech et al. 2007; Kenstavičienè et al. 2009).

Salicin is known as "nature's aspirin" and is metabolized upon ingestion via hydrolysis to salicyl alcohol (saligenin) followed by the formation of salicylic acid. However, salicin is not the only natural metabolite found in willow's bark. Chromatographic analysis with mass spectrometry detection revealed number of salicylate compounds including saligenin, salicylic acid, isosalicin, salidroside, picein,triandrin, salicoylsalicin, salicortin, isosalipurpuroside, and salipurpuroside (Kammerer et al. 2005). More comprehensive studies of willow bark extracts showed additionally the presence of some polyphenolic compounds and flavonoids such as catechin,amelopsin, taxifolin, 7-O-methyltaxifolin-3'-O-glucoside and 7-O-methyltaxifolin, with high antioxidant and radical scavenging activities. The presence of the latest group may explain discrepancies in clinical efficacy of salicin and related compounds. Numbers of clinical human and animal trials with willow bark extracts provide some confusing results. Some prove its effectiveness while the others not, but general conclusion is rather supporting the view that willow bark extract is effective as an analgesic and anti-inflammatory agent (Shara and Stohs 2015).
Recently, there is much interest in willow bark extracts as antitumor agent inhibiting angiogenesis, the process, which supplies oxygen and nutrients to tumor cells. This was reported that willow bark extract may suppress the growth and induce apoptosis in human colon and lung cancer cells in vitro (Hostanska et al. 2007). Other studies reported the extract to kill $75-80 \%$ of acute lymphoblastic leukemia and acute myeloid leukemia cells harvested from human patients, in vitro (El-Shemy et al. 2007).

Bark extracts are components of number of market preparations. They show some advantages over the aspirin (acetylsalicylic acid) as they do not show such side effects and are less stomach irritating then aspirin (Highfield and Kemper 1999). Besides, due to the presence of other phenolics in the extract the effective doses range between 120 and $240 \mathrm{mg}$ salicin while for the same effect $500 \mathrm{mg}$ of aspirin is recommended. But, for the safety reason individuals allergic to aspirin should avoid willow bark extracts as well.

For the application of salicin in medicine, health promoting products and nutraceuticals the industrial protocols for its isolation and purification have been developed and patented (Wang et al. 2016). The extracts performed with "green solvents" (ethanolwater mixtures) are purified by filtration on resin column to obtain product of about $70 \%$ purity. The process is low cost, high efficiency and environmentally friendly. Other proposed methods include hot water treatment for the extraction of non-cell-wall components. The aqueous treatment of the bark at $80{ }^{\circ} \mathrm{C}$ liberated the extract in $>20 \%$ yield under unpressurized conditions (Dou 2018; Dou et al. 2018). The major components of this extract were picein, triandrin and catechin with an overall yield of up to $14 \%$.

Taking under consideration species chemical discrepancies, future prospects for breeding new lines should consider three aspects: a high content of phenolic substances; a high bioethanol yield; and a high resistance to rust (Dou 2018). For phytochemicals, new technics for up scaled purification of desired substances need to be developed. Willow biomass holds much potential for creating greater value from willow biomass by utilizing the phenolic substances and sclerenchyma fibers of the bark and converting the debarked biomass e.g. into bioethanol, bio-char and energy (Dou 2018). 
Black locust (Robinia pseudoacacia)

The black locust is the leguminous woody species, very effective at colonizing an area, because it freely branches and in Europe is recognized as most dangerous invasive species, as a third species after poplars and eucalyptus for wood production. It shows a higher yield and a faster harvest time than any other woody plant species. Thus, it is very attractive biomass plant (Fig. 4).

The wood of black locust belongs to species noted for their natural decay resistance similar to oak or cherry wood. Due to the decay resistance and high natural durability, black locust hardwood has been used for outdoor fence posts as well as for timber (e.g., beam, railroad sleepers). The heartwood of robinia is highly demanded by users, especially for long, lasting outdoor applications. $R$. pseudoacacia wood has also long been used to age vinegars and, more recently, wine (Sanz et al. 2012). The air transfer efficiency through the pores of this wood favours efficient acidification rates and affects the phenolic composition and sensory quality of vinegar.

The biomass of robinia can be used as a substrate in an integrated biorefinery, including in the production of second-generation biofuels (Stolarski et al. 2015). A biorefinery uses the concept of separation and utilization of all the organic fractions obtained from lignocellulose. Processing the fractions, which are not used in the ethanol production helps to improve the economic balance of the installation. Thus, the residues and waste generated by wood industry can play important role for the implementation of more cleaner and sustainable economy, as wooden biomasses represents an important source of chemicals useful for different industrial sectors (Di Maria et al. 2018).

The available data on the content of natural products show that Robinia pseudoacacia is rich in secondary metabolites (Table 10). The trunk, which consists of the bark and hardwood contains different classes of natural products. The bark has been rich with triterpene saponins, while the hardwood contains wide range of natural products of phenolic, stilbenic or terpenoid structures.

In the $n$-hexane and ethanoic extracts of robinia hardwood, twenty-eight volatile compounds such as acids, fatty acids, aliphatic hydrocarbons, aromatic hydrocarbons, esters, fatty acids ester, pure hydrocarbon oils or mineral oils were identified with GC-MS analysis. The dominant compound was resorcinol (1,3-benzendiol); (52\% of total), buthexadecanoic acid, trimethylsilyl ester, 9,12-octadecadienoic acid, (Z,Z)-, tetradecane, bis(2-ethylhexyl) phthalate, hexadecane, 9,12,15-octadecatrien-1-ol, (Z,Z,Z)-, hexadecanoic acid and 9,12-octadecadienoic acid (Z,Z)were also quite abundant (Hosseinihashemi et al. 2013). Very comprehensive analysis of volatiles in acacia bark grown in Turkey was performed using SPME and GC-FID/MS methods (Özgenç et al. 2017).

Sanz et al. (2012), analysing wines aged in the barrels made of oak and acacia hardwood, identified 43 nonanthocyanic phenolic compounds in both wines by LC-DAD-ESI/MS. Furthermore, wines aged in acacia barrels contained additionally 15 compounds of acacia origin. They included dihydrorobinetin,

Table 10 Phytochemicals identified in Robinia pseudoacacia

\begin{tabular}{|c|c|c|}
\hline $\begin{array}{l}\text { Part of } \\
\text { plant }\end{array}$ & Metabolite & References \\
\hline \multirow{6}{*}{$\begin{array}{l}\text { Hard } \\
\text { wood }\end{array}$} & Dihydrorobinetin, dobinetin 2,4-dihydroxybenzaldehyde & Sanz et al. (2012) \\
\hline & tetrahydroxydihydroflavonol, fustin, butin, trihydroxymethoxydihydroflavonol, 2,4- & Latorraca et al.(2011) \\
\hline & dihydroxybenzoic acid & Sergent et al. (2014) \\
\hline & Resveratrol, piceatannol & Sergent et al. (2014) \\
\hline & $\begin{array}{l}\text { Norathyriol, urolithin } \mathrm{C} \text {, urolithin M6, catechin lactone A, bis(2- } \\
\text { ethylhexyl)phthalate }\end{array}$ & Hong et al. (2017) \\
\hline & Secundiflorol, mucronulatol, isomucronulatol, isovestitol & Tian and Mac Laughlin (2000) \\
\hline \multirow[t]{2}{*}{ Bark } & 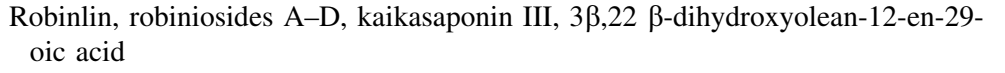 & $\begin{array}{l}\text { Tian et al. (2001) and Cui et al. } \\
\text { (1992) }\end{array}$ \\
\hline & Robiniosides E-J, catechins, (E)-coniferyl alcohol, phenolic acids & $\begin{array}{l}\text { Cui et al. (1993) and Di Maria } \\
\text { et al. (2018) }\end{array}$ \\
\hline
\end{tabular}


robinetin, 2,4-dihydroxybenzaldehyde, a tetrahydroxydihydroflavonol, fustin, butin, a trihydroxymethoxydihydroflavonol and 2,4-dihydroxybenzoic acid, with dihydrorobinetin being most abundant. Another comprehensive metabolic profiling of hardwood natural products allowed identification over 60 compounds, based on their spectroscopic characteristics (Sanz et al. 2011).

Two stilbenic componds, resveratrol and piceatannol, together with dihydrorobinetin were identified in hardwood (Sergent et al. 2014). These stilbens are known as highly antioxidant compounds present in number of plants, but predominantly in grapes.

Five triterpene glycosides, robiniosides A-D, were identified in the robinia bark. These included as 3-O- $\alpha-$ L-rhamnopyranosyl( $1 \rightarrow 2$ )- $\beta$-D-glucopyranosyl $(1 \rightarrow$ $2)$ - $\beta$-D-glucuronopyranosyl $3 \beta, 22 \beta$-dihydroxyolean12-en-29-oic acid, 3- $O$ - $\alpha$-L-rhamnopyranosyl( $1 \rightarrow$ $2)$ - $\beta$-D-galactopyranosyl $(1 \rightarrow 2) \quad \beta$-D-glucuronopyranosyl $3 \beta, 22 \beta$,24-trihydroxyolean-12-en-29-oic acid (oxytrogenin), 3-O- $\alpha$-L-rhamnopyranosyl( $1 \rightarrow 2$ )- $\beta$ D-glucopyranosyl $(1 \rightarrow 2)-\beta$-D glucuronopyranosyloxytrogen, 3-O- $\alpha$-L-rhamnopyranosyl $(1 \rightarrow 2)-\beta-\mathrm{D}$ galactopyranosyl $(1 \rightarrow 2)$ - $\beta$-D-glucuronopyranosyloxytrogenin $22-O-\alpha$-L-rhamnopyranoside, $3-O$ - $\alpha$-L-rhamnopyranosyl( $1 \rightarrow 2$ )- $\beta$-D-glucopyranosyl $(1 \rightarrow 2)$ - $\beta$-Dglucuronopyranosyloxytrogenin 22- $O$ - $\alpha$-L-rhamnopyranoside, kaikasaponin III and 3-O- $\alpha$-L-rhamnopyra$\operatorname{nosyl}(1 \rightarrow 2)$ - $\beta$-D-galactopyranosyl $(1 \rightarrow 2)$ - $\beta$-D-glucuronopyranosyl 3- $\beta$-22- $\beta$-dihydroxyolean-12-en-29oic acid (Cui et al. 1992). The same group of authors later on identified additionally six triterpene glycosides, Robiniosides E-J, including abrisapogenol B 3-O- $\alpha$-Lrhamnopyranosyl( $1 \rightarrow 2$ )- $\beta$-D-galactopyranosyl $(1 \rightarrow 2)$ $\beta$-D-glucuronopyranoside, abrisapogenol B 3-O- $\alpha$-Lrhamnopyranosyl $(1 \rightarrow 2)$ - $\beta$-D-glucopyranosyl $(1 \rightarrow 2)$ $\beta$-D-glucuronopyranoside, $\quad 3-O$ - $\alpha$-L-rhamnopyranosyl $(1 \rightarrow 2)$ - $\beta$-D-galactopyranosyl( $1 \rightarrow 2$ )- $\beta$-Dglucuronopyranosylabrisapogenol B 22- $O$ - $\alpha$-L-rhamnopyranoside, 3- $O$ - $\alpha$-L-rhamnopyranosyl $(1 \rightarrow 2)$ - $\beta$-D-glucopyranosyl $(1 \rightarrow 2)$ - $\beta$-D-glucuronopyranosylabrisapogenol B 22$O$ - $\alpha$-L-rhamnopyranoside, $\quad 3-O$ - $\alpha$-L-rhamnopyranosyl $(1 \rightarrow 2)$ - $\beta$-D-galactopyranosyl $(1 \rightarrow 2)$ - $\beta$-D-glucuronopyranosylabrisapogenol E $30-\mathrm{O}-\beta$-D-apiofuranosyl $(1 \rightarrow 6)-\beta$-D-glucopyranoside and 3-O- $\alpha$-L-rhamnopy$\operatorname{ranosyl}(1 \rightarrow 2)$ - $\beta$-D-glucopyranosyl $(1 \rightarrow 2)$ - $\beta$-D-glucuronopyranosylabrisapogenol E $30-O-\beta$-D-apiofura$\operatorname{nosyl}(1 \rightarrow 6)$ - $\beta$-D-glucopyranoside (Cui et al. 1993). Other identified compounds include robinin
(kaempferol-3-O-ramnosyl-galactosyl-7-ramnoside) and acacetin-7- $O$-rutoside, diosmetin, luteolin, apigenin but also isomucronulatol, mucronulatol, secundiflorol and isovestitol glycosides (Ebel et al. 1970; Kaneta et al. 1980; Veitch et al. 2010).

Dutu and Dinu (2006) showed that the vegetal product of acacia flowers contains polyphenol carboxylic acids, flavones, proanthocyanidins, tannins and triterpenic saponins. The polyphenols (expressed in caffeic acid) were detected at the level of 363.5-395.5 mg\%, flavones (expressed in rutin)92.7-102.5 $\mathrm{mg} \%$. The comparison of the flavonoid chemistry of leaves and flowers of $R$. pseudoacacia using LC-UV and LC-MS showed that flavone 7-Oglycosides, particularly acacetin, predominated in the leaves, whereas flavonol 3,7-di- $O$-glycosides mainly in the flowers (Veitch et al. 2010). Phenolic compounds available within the leaves and flowers have been proven to have a strong antiradical activity ( $\mathrm{Ji}$ et al. 2012; Marinas et al. 2014).

In the roots of black locust, the apigenin, naringenin, dihydroxyflavone, $4^{\prime}, 7$-isoliquiritigenin and an unusual tetrahydrochromeno[4,3- $\beta$ ]indole (type ana$\log$ of medicarpin), have been isolated (Dejon et al. 2013). The dried, unripe fruits of $R$. pseudoacacia contained bioquercetin (quercetin 3- $O$ - $\beta$-D-galactopyranosyl-L-rhamnopyranoside); (Maksyutina 1967).

The hardwood of acacia can be a good source of biologically active phytochemicals for different industries as extracts or individual compounds, which show inhibitory activities against number of microorganisms. The method for isolation of different fractions of natural products was optimized. It was documented that optimal extraction solvent for dihydrorobinetin was $\mathrm{EtOH} / \mathrm{H} 2 \mathrm{O}(50 / 50)$. The dihydrorobinetin was purified over $95 \%$ using centrifugal partition chromatography (CPC); (Destandau et al. 2016). The method was simple, not expensive and environmentally friendly.

Water soluble extract showed protective effect against Sphaerothecafuligiena, the powdery mildew fungus, which is one of the most destructive foliar diseases of cucurbits. Effectivity of the extract was higher than $80 \%$ and can be recognized as very effective natural fungicide, especially interesting for organic and indoor farming (Zhang et al. 2008).

The antibacterial activity of the crude extract and the solvent fractions (hexane, chloroform, ethyl acetate and butanol) were evaluated against 


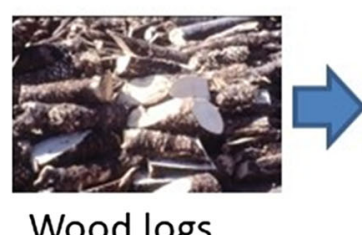

Wood logs

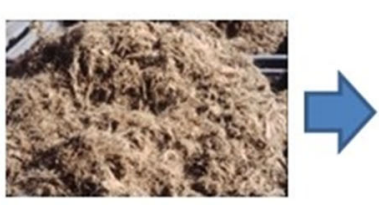

Flaked wood

\section{Purification and \\ separation by \\ chromatography}

Fig. 5 General approach in extraction, isolation and characterization of woody plant phytochemicals

Streptococcus mutans and Porphyromonasgingivalis (Patra et al. 2015). The most active were hexane and chloroform fraction containing hydrophobic compounds giving over $90 \%$ inhibition. This indicated that acacia hydrophobic compounds can find clinical application as disinfectants for the treatment of dental plaque and periodontal inflammatory diseases.

The wood decay resistance of acacia is being assigned to the content of two active principles dihydrorobitenin and robitenin. Thus, the extracts of hardwood of acacia can be applied as natural, ecologically green product for outdoor woody furniture, construction and wooden crafts preservation. It was shown that saw dust from Eucalyptus regnans, a normally nondurable wood, was no more durable after impregnation with up to $1 \%$ robinetin or dihydrorobinetin than were unimpregnated controls (Rudman 1963). As for optimal biofuel production it is recommended to treat hardwood with hot water to remove some interfering components, this wastewater can be used for separation of biologically active principles (Kačík et al. 2016).

Some toxicity to mammals were reported when chewing acacia wood. The toxic principle was not proven but it is believed that glycoproteins (lectinsrobin, robitin, phasin) and/or triterpene saponins are responsible factor (Horejsi et al. 1978).

\section{Extraction, isolation, analysis and application of phytochemicals from bioenergy crops}

The subsequent stages of the use of phytochemicals from plants are extraction, isolation and chemical characterization of bioactive compounds, as well as evaluation of their properties and application potential (Sasidharan et al. 2011). For energy crops, the biggest problem in extraction is the scale and the process of biomass preparation. As to the scale, specialized machinery is necessary with high throughput. They are needed for preparation of plant material, which must be meshed before extraction. Several methods has been developed for the extraction of high-value bioactive compounds from plants, such as organic solvent extraction, maceration, hydrodistillation, lowpressure solvent extraction, hydrothermal processing and supercritical extraction. Proper selection of extraction solvents is essential for isolation of wide range phytochemicals having different polarities. The composition of the final extract may influence extract efficacy when used in therapy or as active food ingredient (Shara and Stohs 2015) Recently, significant emphasis on developing "green" technologies of extraction is more often observed (Attard et al. 2015). Non-toxic, cheap and environmentally friendly solvents and their lower amounts are very desirable in the case of clean technology of extraction. The extraction results in the mixture of compounds so called crude extract. The isolation of individual compounds or purified fraction is a long and often arduous process and need individual development for different plant 


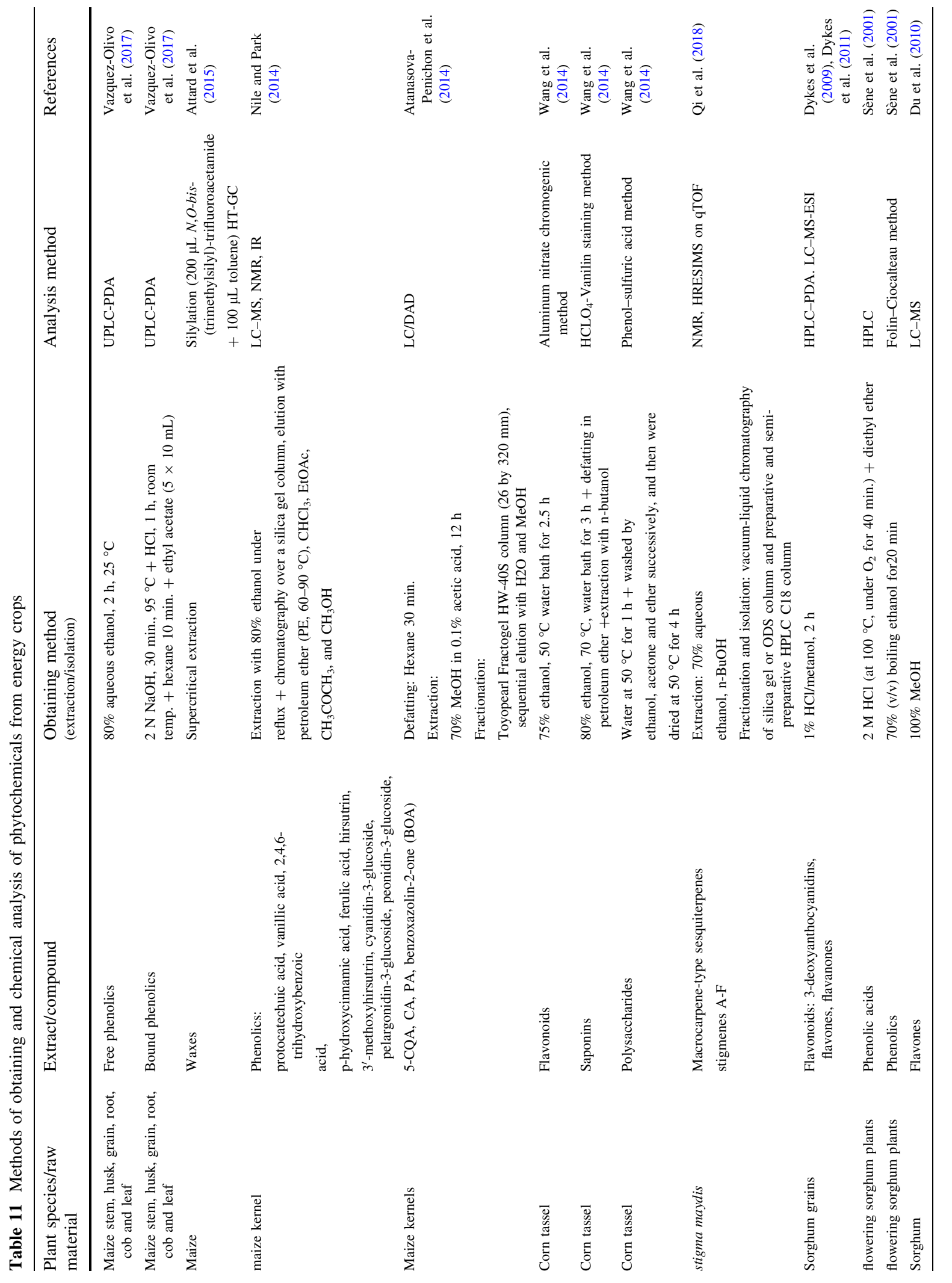




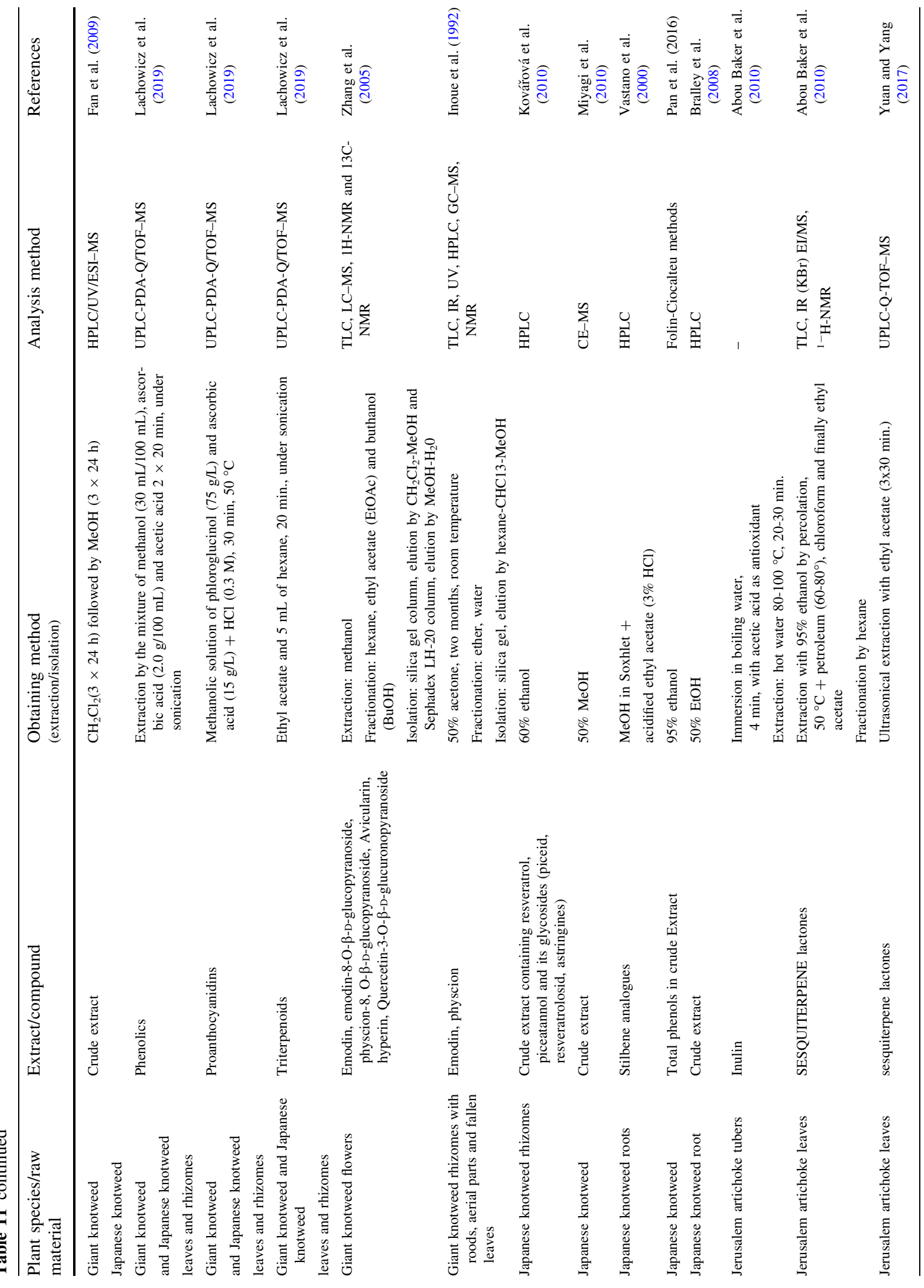




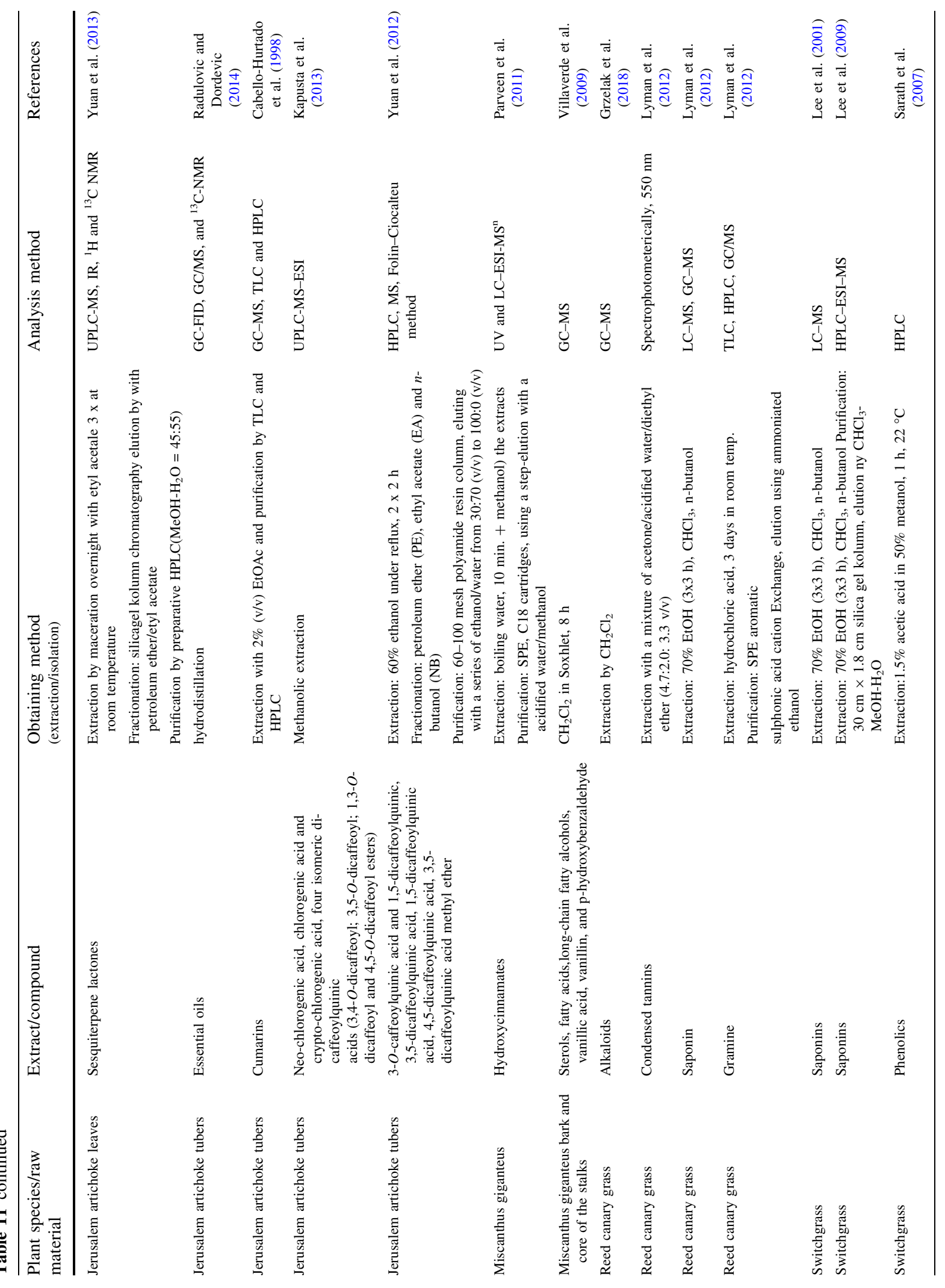




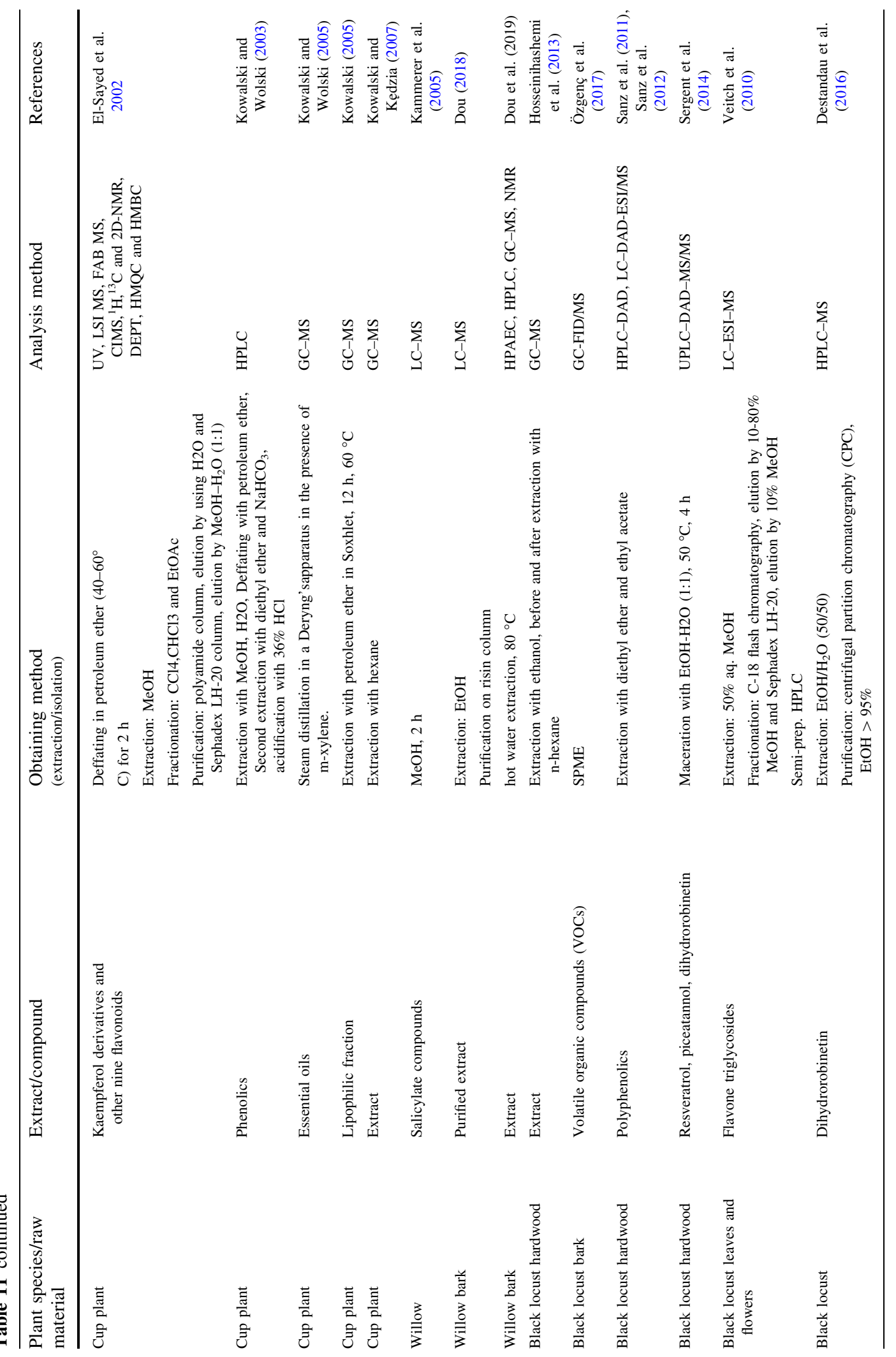




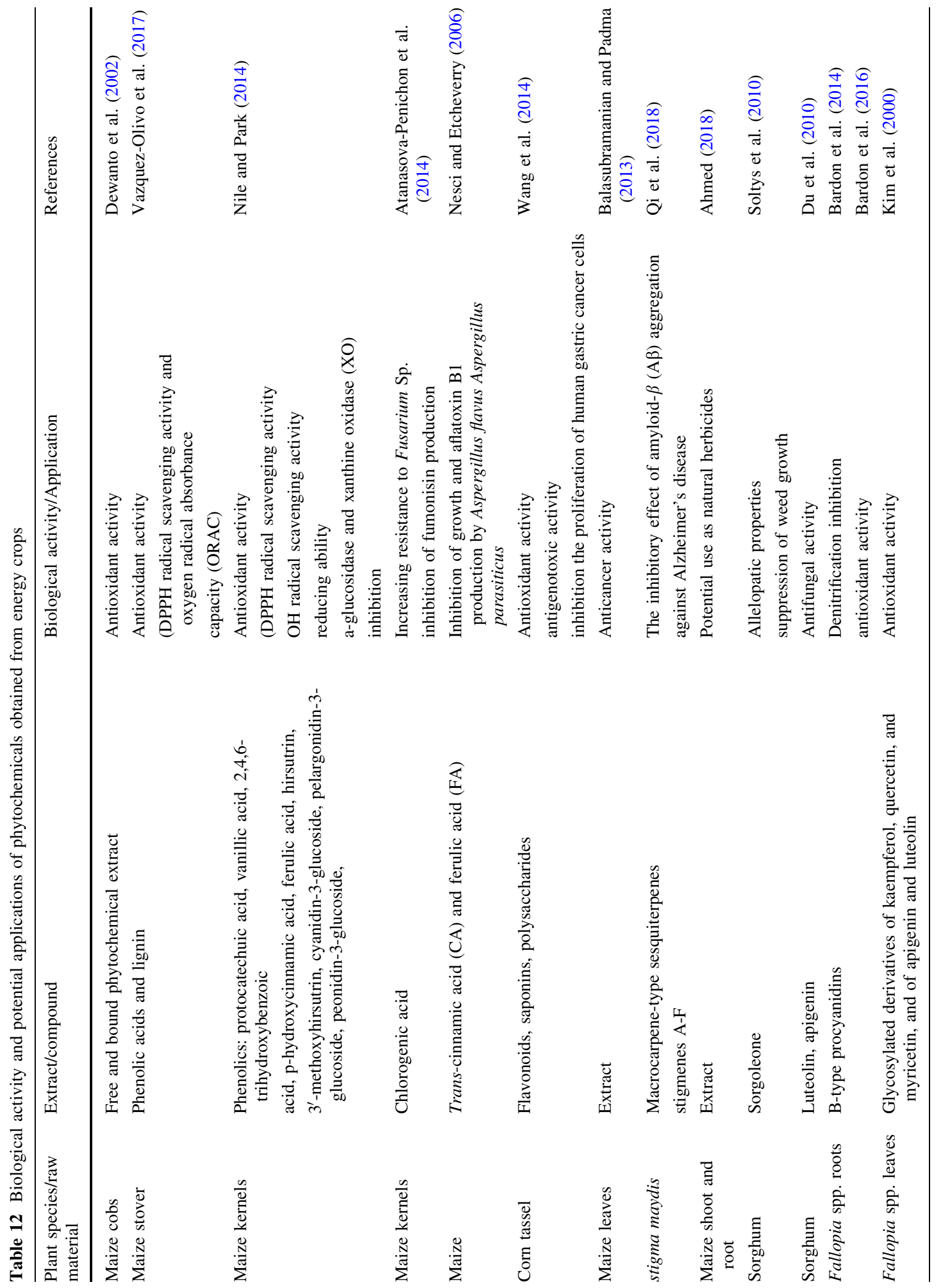




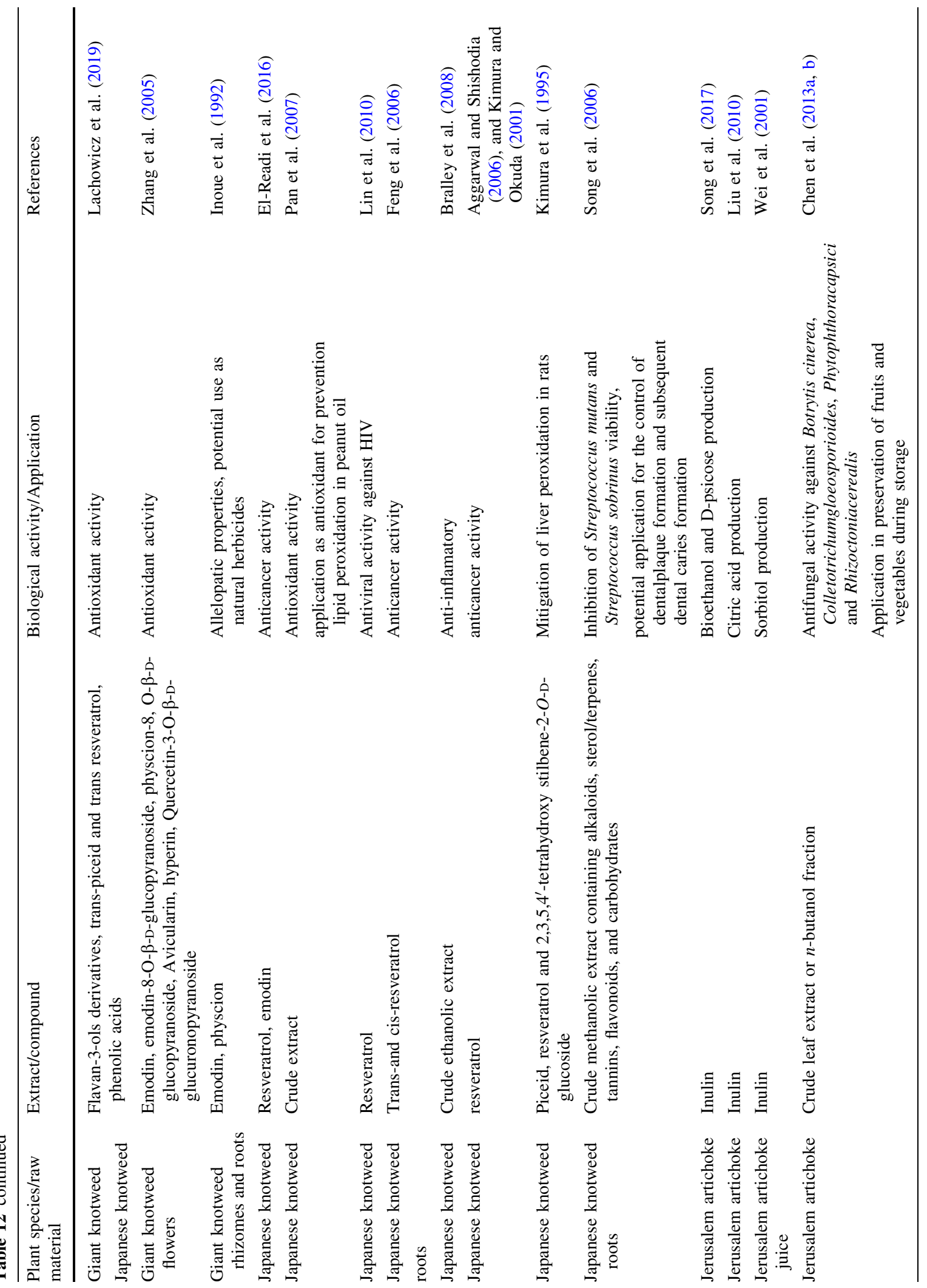




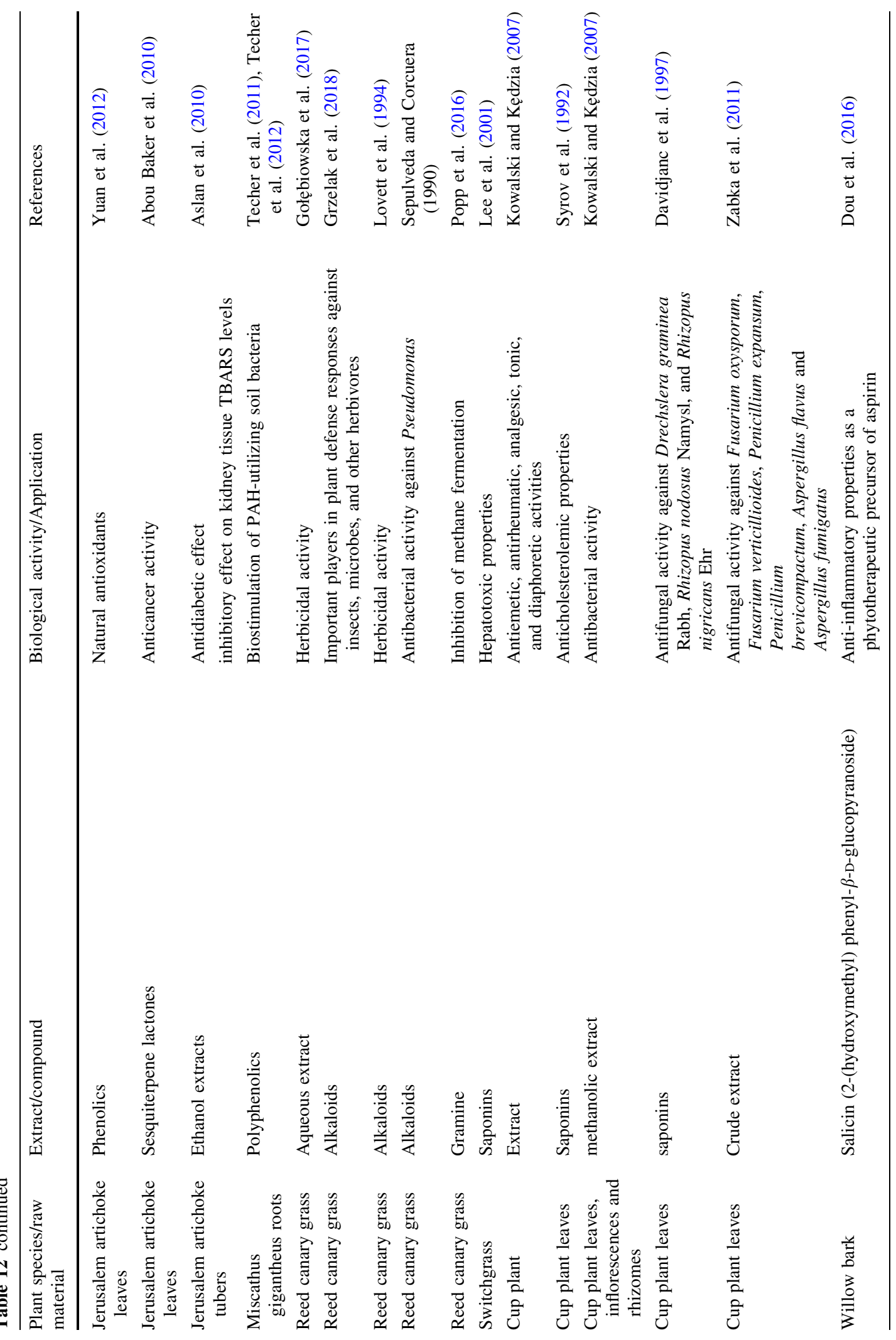




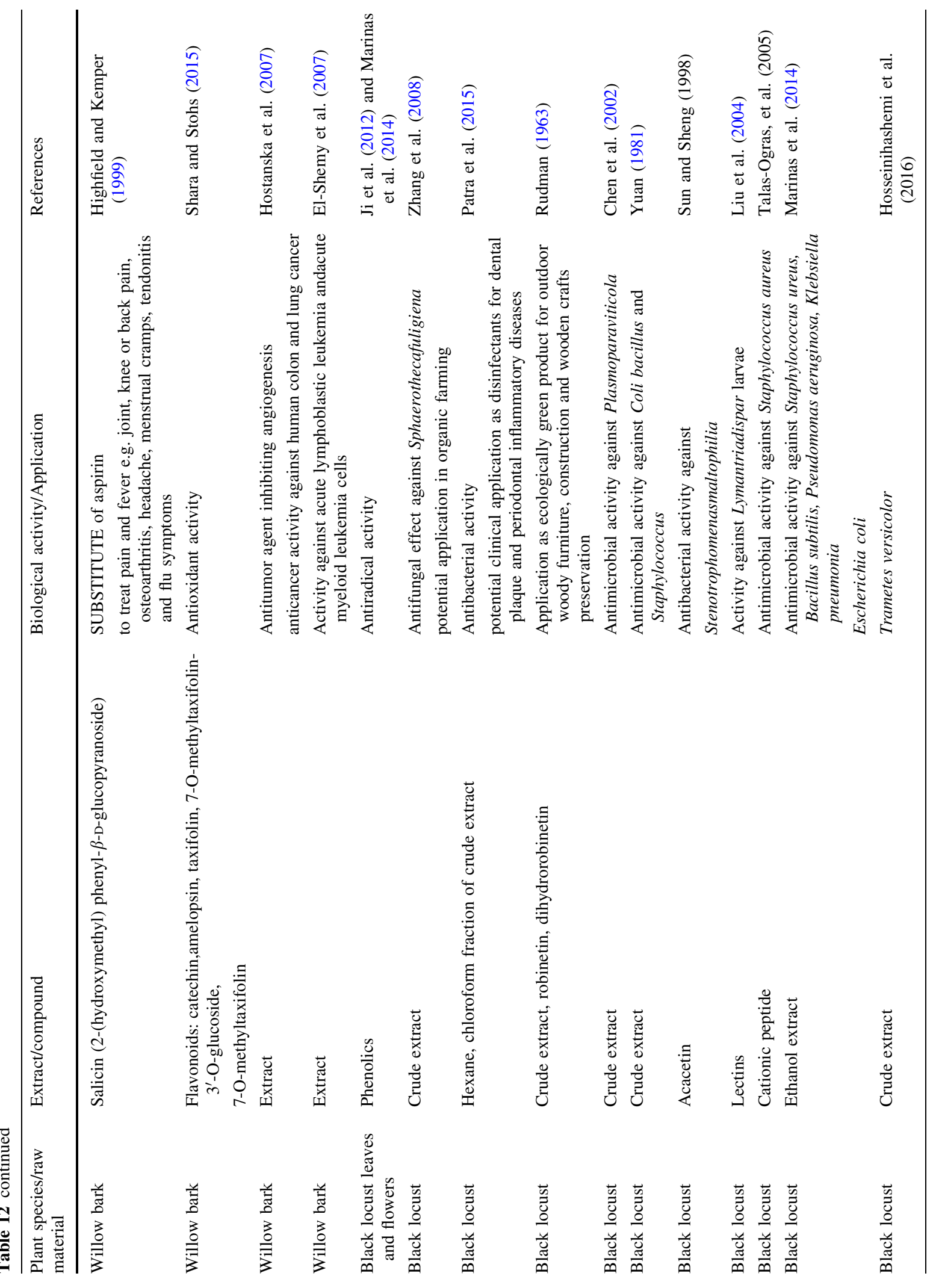




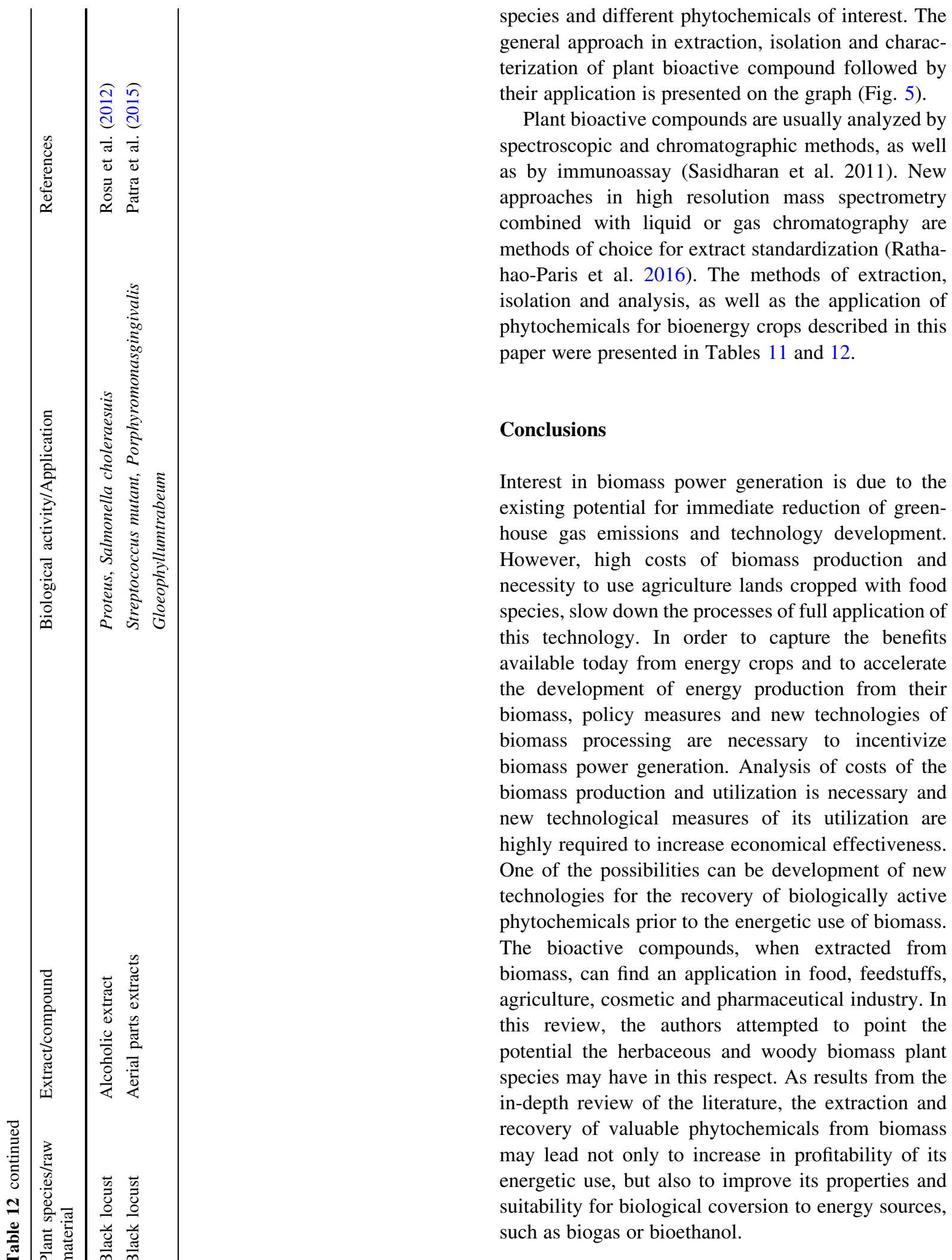


Acknowledgements The present research work has been conducted in the National Science Centre (NCN) project No. 2014/15/N/NZ9/01127 (MO), and HORIZON 2020 project "New Strategies on Bioeconomy in Poland" which has received funding from the European Commission under the call: H2020 WIDESPREAD-2014-2, topic: ERA Chairs, grant agreement No. 669062 (WO).

Open Access This article is distributed under the terms of the Creative Commons Attribution 4.0 International License (http:// creativecommons.org/licenses/by/4.0/), which permits unrestricted use, distribution, and reproduction in any medium, provided you give appropriate credit to the original author(s) and the source, provide a link to the Creative Commons license, and indicate if changes were made.

\section{References}

Abou Baker DH, El Gengaihi SE, AboulAnein AH et al (2010) Biochemical study of some active ingredients in Helianthus tuberosus L. Med Aromat Plant SciBiotechnol 4:66-68

Aggarwal BB, Shishodia S (2006) Molecular targets of dietary agents for prevention and therapy of cancer. Biochem Pharmacol 71:1397-1421

Aguilera AG, Alpert P, Dukes JS et al (2010) Impacts of the invasive plant Fallopia japonica (Houtt.) on plant communities and ecosystem processes. Biol Invasions 12:1243-1252

Ahmed HM (2018) Phytochemical screening, total phenolic content and phytotoxic activity of corn (Zea mays) extracts against some indicator species. Nat Prod Res 32:714-718

Ahmed MS, El-Sakhawy FS, Soliman SN et al (2005) Phytochemical and biological study of Helianthus tuberosus L. Egypt J Biomed Sci 18:134-147

Al-Snafi AE (2018) Medical importance of Helianthus tuberosus- a review. IAJPS 05:2159-2166

Alvim R (1978) Seasonal variation in the hormone content of willow. Plant Physiol 62:779-780

Andreo CS, Orellano EG, Niemeyer HM (1984) Uncoupling of spinach thylakoids by gramine. Z Naturforsh 39:746-748

Aslan M, Orhan N, Orhan DD et al (2010) Hypoglycemic activity and antioxidant potential of some medicinal plants traditionally used in Turkey for diabetes. J Ethnopharmacol 128:384-389

Atanasova-Penichon V, Bernillon S, Marchegay G et al (2014) Bioguided isolation, characterization, and biotransformation by Fusarium verticillioides of maize kernel compounds that inhibit fumonisin production. Mol Plant Microbe Interact 27:1148-1158

Attard TM, Theeuwes E, Gomez LD et al (2015) Supercritical extraction as an effective first-step in a maize stover biorefinery. RSC Adv 5:43831-43838

Awika JM, Rooney LW (2004) Sorghum phytochemicals and their potential impact on human health. Phytochemistry 65:1199-1221
Azmir J, Zaidul ISM, Rahman MM et al (2013) Techniques for extrac-tion of bioactive compounds from plant materials: a review. J Food Eng 117:426-436

Baba H, YaoitaY Kikuchi M (2005) Sesquiterpenoids from the leaves of Helianthus tuberosus L. J Tohoku Pharm Univ 52:21-25

Bais HP, Vepachedu R, Gilroy S et al (2003) Allelopathy and exotic plant invasion: from molecules and genes to species interactions. Science 301:1377-1380

Balasubramanian K, Padma PR (2013) Anticancer activity of Zea mays leaf extracts on oxidative stress-induced Hep2 cells. J Acupunct Meridian Stud 6:149-158

Bardon C, Piola F, Bellvert F et al (2014) Evidence for biological denitrification inhibition (BDI) by plant secondary metabolites. New Phytol 204:620-630

Bardon C, Haichar FZ, Meiffren G et al (2016) Identification of B-type procyanidins in Fallopia spp. involved in biological denitrification inhibition. Environ Microbiol 18:644-655

Barney JN, Tharayil N, DiTommaso A et al (2006) The biology of invasive alien plants in Canada. 5. Polygonum cuspidatum Sieb. \& Zucc. [= Fallopia japonica (Houtt.) Ronse Decr.]. Can J Plant Sci 86:887-905

Bralley EE, Greenspan P, Hargrove JL et al (2008) Topical antiinflammatory activity of Polygonum cuspidatum extract in the TPA model of mouse ear inflammation. J Inflamm $5: 1-5$

Brosse N, Dufour A, Meng X et al (2012) Miscanthus: a fastgrowing crop for biofuels and chemicals production. Biofuel Bioprod Biorefin 6:580-598

Cabello-Hurtado F, Durst F, Jorrin JV et al (1998) Coumarins in Helianthus tuberosus: characterization, induced accumulation and biosynthesis. Phytochemistry 49:1029-1036

Chae S, Lee S, Kang SS et al (2002) Flavone glucosides from the leaves of Helianthus tuberosus. Nat Prod Sci 8:141-143

Charnikhova TV, Gaus K, Lumbroso A et al (2018) Zeapyranolactone - a novel strigolactone from maize. Phytochem Lett 24:172-178

Chen F, Long X, Yu M et al (2013a) Phenolics and antifungal activities analysis in industrial crop Jerusalem artichoke (Helianthus tuberosus L.) leaves. Ind Crop Prod 47:339-345

Chen H, Tuck T, Ji X et al (2013b) Quality assessment of Japanese knotweed (Fallopia japonica) grown on Prince Edward Island as a source of resveratrol. J Agric Food Chem 61:6383-6392

Chen F, Long X, Liu Z et al (2014) Analysis of phenolic acids of Jerusalem artichoke (Helianthus tuberosus L.) responding to salt-stress by liquid chromatography/tandem mass spectrometry. Sci World J 2014:1-8

Clifton-Brown JC, Breuer J, Jones MB (2007) Carbon mitigation by the energy crop Miscanthus. Glob Change Biol 13:2296-2307

Corno L, Pilu R, Adani F (2014) Arundo donax L.: a non-food crop for bioenergy and bio-compound production. Biotechnol Adv 32:1535-1549

Coulman BE, Woods DL, Clark KW (1977) Distribution within the plant, variation with maturity and heritability of gramine and hordenine in reed canarygrass. Can J Plant Sci 57:771-777 
Cui B, Kinjo J, Nohara T (1992) Triterpene glycosides from the bark of Robinia pseudoacacia L. I. Chem Pharm Bull 40:2995-2999

Cui B, Kinjo J, Nohara T (1993) Triperpene glycosides from thebark of Robinia pseudoacacia L. II. Chem Pharm Bull 41:553-556

D'Mello JPF (2000) Anti-nutritional factors and mycotoxins. Farm animal metabolism and nutrition. CAB International, Wallingford, pp 383-403

Davidjanc ES, Kartaševa IA, Nešin IW (1997) The effect of triterpene glycosides of Silphium perfoliatum L. on phytopathogenic fungi. Rast Resursy 4:93-98

Dejon L, Mohammed H, Du P et al (2013) Synthesis of chromenoindole derivatives from Robinia pseudoacacia. Med Chem Comm 4:1580-1583

Destandau E, Charpentier JP, Bostyn S et al (2016) Gram-scale purification of dihydrorobinetin from Robinia pseudoacacia L. wood by centrifugal partition chromatography. Separations 3:23

Dewanto V, Wu X, Liu RH (2002) Processed sweet corn has higher antioxidant activity. J Agric Food Chem 50:4959-4964

Di Maria F, Segoloni E, Lavagnolo MC (2018) Extraction of bio-chemicals for pharmaceutical and food industryfrom myrocarpusfrondosus, Robinia presudoacacia and three quercusspecies. Waste Biom Valor 1-7

Donker JD, Marten GC, Jordan RN et al (1976) Effects of drying on forage quality of alfalfa and reed canarygrass fed to lambs. J Anim Sci 42:180-184

Dou J (2018) Fractionation of willow bark forcombined production of extracts andfiber bundles. Doctoral dissertations 221/2018, Aalto University, Helsinki, Finland

Dou J, Galvis L, Holopainen-Mantila U et al (2016) Morphology and overall chemical characterization of willow (Salix sp.) inner bark and wood: toward controlled deconstruction of willow biomass. ACS Sustain Chem Eng 4:3871-3876

Dou J, Xu W, Koivisto JJ et al (2018) Characteristics of hot water extracts from the bark of cultivated willow (Salix sp.). ACS Sustain Chem Eng 6:5566-5573

Du Y, Chu H, Wang M et al (2010) Identification of flavone phytoalexins and a pathogeninducible flavone synthase II gene (SbFNSII) in sorghum. J Exp Bot 61:983-994

Duodu KG, Awika JM (2019) Phytochemical-related healthpromoting attributes of sorghum and millets. In: Taylor JRN, Duodu KG (eds) Sorghum and millets, chemistry, technology and nutritional attributes, 2nd edn. AACC International, Eagan, pp 225-258

Dutu LE, Dinu M (2006) Contributions to the pharmacognostic study of acacia flowers (Robinia pseudoacacia L., Fabaceae). Farmacia 54:70-77

Duynisveld GW, Slominski BA, Wittenberg KM et al (1990) Alkaloid content of reed canarygrass (Phalaris arundinacea L.) as determined by gas-liquid chromatography. Can J Plant Sci 70:1097-1103

Dykes L, Seitz L, Rooney WL et al (2009) Flavonoid composition of red sorghum genotypes. Food Chem 116:313-317

Dykes L, Peterson GC, Rooney WL et al (2011) Flavonoid composition of lemon-yellow sorghum genotypes. Food Chem 128:173-179
Ebel J, Barz W, Grisebach H (1970) Biosynthesis of acacetin in Robinia pseudacacia: incorporation of multiple labeled $p$ methoxycinnamic acid. Phytochemistry 9:1529-1534

El-Readi MZ, Eid SY, Al-Amodi HS et al (2016) Fallopia japonica: bioactive secondary metabolites and molecular mode of anticancer. J Tradit Med Clin Nat 5:193-213

El-Sayed NH, Wojcińska M, Drost-Karbowska K et al (2002) Kaempferol triosides from Silphium perfoliatum. Phytochemistry 60:835-838

El-Shemy HA, Aboul-Enein AM, Aboul-Enein KM, Fujita K (2007) Willow leaves extracts contain anti-tumor agents effectiveagainst three cell types. PLoS ONE 2:1-10

Eom MR, Weon JB, Jung YS et al (2017) Simultaneous determination of four compounds, campesterol, emodin $8-O-\beta$ D-glucopyranoside, quercetin, and isoquercitrin in Reynoutria sachalinensis by high-performance liquid chromatography-diode array detector. Pharmacogn Mag 13:S258-S261

Fałtynowicz H, Kaczmarczyk J, Kułażyński M (2015) Preparation and characterization of activated carbons from biomass material-giant knotweed (Reynoutria sachalinensis). Open Chem 13:1150-1156

Fan PH, Hay AE, Marston A et al (2009) Chemical variability of the invasive neophytes Polygonum cuspidatum Sieb. and Zucc. and Polygonum sachalinensis F. Schmidt ex Maxim. Biochem Syst Ecol 37:24-34

Feng L, Zhang LF, Yan T et al (2006) Studies on active substance of anticancer effect in Polygonum cuspidatum. Zhong Yao Cai 29:689-691

Fernandez PC, Meiners T, Björkman C, Hilker M (2007) Electrophysiological responses of the blue willow leaf beetle, Phratora vulgatissima, to volatiles of different Salix viminalis genotypes. Entomol Exp Appl 125:157-164

Frelich JR, Marten GC (1972) Factors influencing indole alkaloids in reed canarygrass. Phalaris arundinacea L, Agron Abstr, p 68

Funnell-Harris D, Pedersen JF, Marx DB (2008) Effect of sorghum seedlings, and previous crop, on soil fluorescent Pseudomonas spp. Plant Soil 311:173-187

Gansberger M, Montgomery LF, Liebhard P (2015) Botanical characteristics, crop management and potential of Silphium perfoliatum L. as a renewable resource for biogas production: a review. Ind Crop Prod 63:362-372

Ghimire BK, Seong ES, Nguyen TX et al (2016) Assessment of morphological and phytochemical attributes in triploid and hexaploid plants of the bioenergy crop Miscanthus $\times$ giganteus. Ind Crop Prod 89:231-243

Gołębiowska H, Kieloch R, Topolski J (2017) Inhibitory effect of aqueous extracts from reed canary grass (Phalaris arundinacea L.) on the development of selected weed species. Electron J Pol Agric Univ. https://doi.org/10. 30825/5.EJPAU.33.2017.20.4

Greenhalf CE, Nowakowski DJ, Yates N et al (2013) The influence of harvest and storage on the properties of and fast pyrolysis products from Miscanthus $\times$ giganteus. Biomass Bioenerg 56:247-259

Grzelak M, Gaweł E, Janyszek-Sołtysiak M et al (2018) Variation in quantitative and qualitative alkaloid composition in Phalaris arundinacea (Poaceae). J Res Appl Agric Eng 63:77-80 
Han R, Wang L, Zhong Q et al (2010) Study on antifungal activity of the extract from the leaves of Helianthus tuberosus. Mod AgricTechnol 5:123-127

Heaton EA, Dohleman FG, Long SP (2008) Meeting US biofuel goals with less land: the potential of Miscanthus. Glob Change Biol 14:2000-2014

Herrmann A (2013) Biogas production from maize: current state, challenges and prospects. 2. Agronomic and environmental aspects. Bioenergy Res 6:372-387

Highfield ES, Kemper KJ (1999) White willow bark (Salix alba). The longwood herbal task force. pp 1-12. http:// www.mcp.edu/herbal/default.htm

Hong SS, Suh HJ, Oh JS (2017) Phenolic chemical constituents of the stem barks of Robinia pseudoacacia. Chem Nat Compd 53:359-361

Horejsi V, Haskovec C, Kocourek S (1978) Studies of lectins. XXXVIII. Isolation and characterization of the lectin from black locust bark (Robinia pseudoacacia L). Biochim Biophys Acta 532:98-104

Hosseinihashemi SK, Safdari V, Kanani S (2013) Comparative chemical composition of $n$-hexane and ethanol extractives from the heartwood of black locust. Asian J Chem 25:929-933

Hostanska K, Jurgenliemk G, Abel G et al (2007) Willow bark extract (BNO1455) and its fractions suppressgrowth and induce apoptosis in human colon and lung cancercells. Cancer Detect Prev 31:129-139

Hou F, Su D, Xu J et al (2016) Enhancedextraction of phenolics and antioxidant capacity from sorghum (Sorghum bicolor L. Moench) shell using ultrasonic-assisted ethanol-water binary solvent. J Food Process Preserv 40:1171-1179

Hovin AW, Marten GC (1975) Distribution of specific alkaloids in reed canarygrass cultivars. Crop Sci 15:705-707

Hovin AW, Solberg Y, Myhr K (1980) Alkaloids in reed canarygrass grown in Norway and the USA. Acm Agric Scand 30:211-215

Hromádková Z, Hirsch J, Ebringerová A (2010) Chemical evaluation of Fallopia species leaves and antioxidant properties of their non-cellulosic polysaccharides. Chem Pap 64:663-672

Huang WY, Cai YZ, Xing J et al (2008) Comparative analysis of bioactivities of four Polygonum species. Planta Med 74:43-49

Huang J, CaiJ Wang J et al (2011) Efficient production of butyric acid from Jerusalem artichoke by immobilized Clostridium tyrobutyricum in a fibrous bed bioreactor. Bioresour Technol 102:3923-3926

Inoue M, Nishimura H, Li HH et al (1992) Allelochemicals from Polygonum sachalinense fr. schm. (Polygonaceae). J Chem Ecol 18:1833-1839

Jantaharn P, Mongkolthanaruk W, Senawong T et al (2018) Bioactive compounds from organic extracts of Helianthus tuberosus L. flowers. Ind Crop Prod 119:57-63

Jayatilake GS, Jayasuriya H, Lee ES et al (1993) Kinase inhibitors from Polygonum cuspidatum. J Nat Prod 56:1805-1810

Ji HF, Du A, Zhang L et al (2012) Effects of drying methods on antioxidant properties in Robinia pseudoacacia L. flowers. J Med Plants Res 6:3233-3239

Kačík F, Ďurkovič J, Kačíková D, Zenková E (2016) Changes in the chemical composition of black locust wood after hot- water pretreatment before bioethanol production. Acta Fac Xyl Zvolen 58:15-23

Kammerer B, Kahlich R, Bieger C et al (2005) HPLC-MS/MS analysis of willow bark extracts contained inpharmaceutical preparations. Phytochem Anal 16:470-478

Kaneta M, Hikichi H, Endo S et al (1980) Identification of flavones in sixteen Leguminosae species. Agric Biol Chem 44:1407-1408

Kapusta I, Szpunar-Krok E, Bobrecka-Jamro D et al (2013) Identification and quantification of phenolic compounds from Jerusalem artichoke (Helianthus tuberosus L.) tubers. J Food Agric Environ 11:601-606

Karl C, Pedersen PA, Schwarz C (1977) A new flavonoacetylglucoside from Salix viminalis. Phytochemistry 16:1117

Kato A, Birchler JA (2006) Induction of tetraploid derivatives of maize in bred lines by nitrous oxide gas treatment. J Hered 97:39-44

Kawai Y, Kumagai H, Kurihara $\mathrm{H}$ et al (2006) $\beta$-Glucosidase inhibitory activities of phenylpropanoid glycosides, vaniscoside A and B from Polygonum sachalinense. Fitoterapia 77:456-459

Kenstavičienè P, Nenortienè P, Kiliuvienè G et al (2009) Application of high-performance liquid chromatography for research of salicin in bark of different varieties of Salix. Medicina (Kaunas) 45:644-651

Kim MH, Park JH, Park CW (2000) Flavonoid chemistry of Fallopia section Fallopia (Polygonaceae). Biochem Syst Ecol 28:433-441

Kim YS, Hwang CS, Shin DH (2005) Volatile constituents from the leaves of Polygonum cuspidatum S. et Z. and their antibacterial activities. Food Microbiol 22:139-144

Kimura Y, Okuda H (2001) Resveratrol isolated from Polygonum cuspidatum root prevents tumor growth and metastasis to lung and tumor-induced neo vascularization in Lewis lung carcinoma-bearing mice. $\mathrm{J}$ Nutr 131:1844-1849

Kimura Y, Kozawa M, Baba K et al (1983) New constitutents of roots of Polygonum cuspidatum. Planta Med 48:164-168

Kimura Y, Okuda H, Kubo M (1995) Effects of stilbenes isolated from medicinal plants on arachidonate metabolism and degranulation in human polymorphonuclear leukocytes. J Ethnopharmacol 45:131-139

Kojima M, Conn EE (1982) Tissue distributions of chlorogenic acid and of enzymes involved in its metabolism in leaves of Sorghum bicolor. Plant Physiol 70:922-925

Konstantinidou-Doltsinis S, Markellou E, Kasselaki AM et al (2006) Efficacy of Milsana (R), a formulated plant extract from Reynoutria sachalinensis, against powdery mildew of tomato (Leveillula taurica). Bio Control 51:375-392

Koštálová Z, Hromádková Z, Paulsen BS et al (2014) Bioactive hemicelluloses alkali-extracted from Fallopia sachalinensis leaves. Carbohyd Res 398:19-24

Kováŕová M, Bartunkova K, Frantik T et al (2010) Factors influencing the production of stilbenes by the knotweed Reynoutria $\times$ bohemica. BMC Plant Biol 10:19

Kowalczyk-Juśko A, Jóźwiakowski K, Gizińska M et al (2012) Jerusalem artichoke (Helianthus tuberosus L.) as renewable energy raw material. Motor Energ Agric 12:117-121

Kowalski R (2005) Analysis of lipophilic fraction from leaves, inflorescences and rhizomes of Silphium perfoliatum L. Acta Soc Bot Pol 74:5-10 
Kowalski R, Kędzia B (2007) Antibacterial activity of Silphium perfoliatum extracts. Pharm Biol 45:494-500

Kowalski R, Wolski T (2003) TLC and HPLC analysis of the phenolic acids in Silphium perfoliatum L. leaves, inflorescences and rhizomes. JPC-Mod TLC 16:230-236

Kowalski R, Wolski T (2005) The chemical composition of essential oils of Silphium perfoliatum L. Flav Frag J 20:306-310

Kumagai H, Kawai Y, Sawano R et al (2005) Antimicrobial substances from rhizomes of the giant knotweed Polygonum sachalinensis against the fish pathogen Photobacterium damselae subsp. piscicida. J Biosci 60:39-94

Lachowicz S, Oszmiański J, Wojdyło A et al (2019) UPLCPDA-Q/TOF-MS identification of bioactive compounds and on-line UPLC-ABTS assay in Fallopia japonica Houtt and Fallopia sachalinensis (F. Schmidt) leaves and rhizomes grown in Poland. Eur Food Res Technol 245:691-706

Latorraca JV, Dünisch O, Koch G (2011) Chemical composition and natural durability of juvenile and mature heartwood of Robinia pseudoacacia L. Ann Braz Acad Sci 83:1059-1068

Lee ST, Stegelmeier BL, Gardner DR et al (2001) The isolation and identification of steroidal sapogenins in switchgrass. J Nat Toxins 10:273-281

Lee ST, Mitchell RB, Wang Z et al (2009) Isolation, characterization, and quantification of steroidal saponins in switchgrass (Panicum virgatum L.). J Agric Food Chem 57:2599-2604

Lin HW, Sun MX, Wang YH et al (2010) Anti-HIV activities of the compounds isolated from Polygonum cuspidatum and Polygonum multiflorum. Planta Med 76:889-892

Liu HX, Yan DH, Zhang XY et al (2004) A preliminary study on the effects of seed lectins from Robinia pseudoacacia on metabolism of Lymantriadispar larvae. For Res 17:15-158

Liu HW, Liu ZP, Liu L et al (2007) Studies on the antifungal activities and chemical components of extracts from Helianthus tuberosus leaves. Nat Prod Res Dev 19:405-409

Liu XY, Chi Z, Liu GL et al (2010) Inulin hydrolysis and citric acid production from inulin using the surface-engineered Yarrowialipolytica displaying inulinase. Metab Eng 12:469-476

Lovett JV, Hoult AH, Christen O (1994) Biologically active secondary metabolites of barley. IV. Hordenine production by different barley lines. J Chem Ecol 20:1945-1954

Luo X, Cui J, Zhang H et al (2018) Ultrasound assisted extraction of polyphenolic compounds from red sorghum (Sorghum bicolor L.) bran and their biological activities and polyphenolic compositions. Ind Crop Prod 112:296-304

Lyman TD, Provenza FD, Villalba JJ et al (2012) Phytochemical complementarities among endophyte-infected tall fescue, reed canarygrass, birdsfoot trefoil and alfalfa affect cattle foraging. Animal 6:676-682

Majak W, McDiarmid RE, Van Ryswyk AL et al (1979) Alkaloid levels in reed canarygrass grown on wet meadows in British Columbia. J Range Manag 32:322-326

Maksyutina NP (1967) Flavonoids of Robinia pseudoacacia. Khim Prir Soedin 3:226-230
Marinas IC, Oprea E, Geana EI et al (2014) Antimicrobial and antioxidant activity of the vegetative and reproductive organs of Robinia pseudoacacia. J Serb Chem Soc 79:1363-1378

Marten GC, Barnes RF, Simons AB et al (1973) Alkaloids and palatability of Phalaris arundinacea L. Agron J 65:199-201

Marten GC, Jordan RM, Hovin AW (1976) Biological significance of reed canarygrass alkaloids and associated palatability variation to grazing sheep and cattle. Agron J 68:909-914

Marten GC, Jordan RM, Hovin AW (1981) Improved lamb performance associated with breeding for alkaloid reduction. Crop Sci 21:295-298

Meyer J, Murray SL, Berger DK (2016) Signals that stop the rot: regulation of secondary metabolite defences in cereals. Physiol Mol Plant Pathol 94:156-166

Miyagi A, Takahashi H, Takahara K et al (2010) Principal component and hierarchical clustering analysis of metabolites in destructive weeds; polygonaceous plants. Metabolomics 6:146-155

Montastruc L, Ajao O, Marinova M et al (2011) Hemicellulose biorefinery for furfural production: energy requirement analysis and minimization. J Sci Technol For Prod Proc $1: 48-53$

Nakagawa R, YasokawaD Ikeda T et al (1996) Purification and characterization of two lectins from callus of Helianthus tuberosus. Biosci Biotechnol Biochem 60:259-262

Nawrot-Hadzik I, Granica S, Domaradzki K et al (2018) Isolation and determination of phenolic glycosides and anthraquinones from rhizomes of various Reynoutria species. Planta Med 84:1118-1126

Nesci AV, Etcheverry MG (2006) Control of Aspergillus growth and aflatoxin production using natural maize phytochemicals under different conditions of water activity. Pest Manag Sci 62:775-784

Nile SH, Park SW (2014) Antioxidant, $\alpha$-glucosidase and xanthine oxidase inhibitory activity of bioactive compounds from maize (Zea mays L.). Chem Biol Drug Des $83: 119-125$

Noge K, Tamogami S (2013) Herbivore-induced phenylacetonitrile is biosynthesized from de novo-synthesized Lphenylalanine in the giant knotweed, Fallopia sachalinensis. FEBS Lett 587:1811-1817

Noge K, Abe M, Tamogami S (2011) Phenylacetonitrile from the giant knotweed, Fallopia sachalinensis, infested by the Japanese beetle, Popillia japonica, is induced by exogenous methyl jasmonate. Molecules 16:6481-6488

Oleszek M, Krzemińska I (2017) Enhancement of biogas production by co-digestion of maize silage with common goldenrod rich in biologically active compounds. BioResources 12:704-714

Oleszek M, Matyka M (2017) Nitrogen fertilization level and cutting affected lignocellulosic crops properties important for biogas production. BioResources 12:8565-8580

Oleszek M, Matyka M (2018) Determination of the efficiency and kinetics of biogas production from energy crops through nitrogen fertilization levels and cutting frequency. BioResources 13:8505-8528 
Oleszek M, Król A, Tys J et al (2014) Comparison of biogas production from wild and cultivated varieties of reed canary grass. Bioresour Technol 156:303-306

Omidbaigi R, Yavari S, Hassani ME et al (2010) Induction of autotetraploidy in dragonhead (Dracocephalum moldavica L.) by colchicine treatment. J Fruit Ornam Plant Res 18:23-35

Otani T, Ito M, Kurihara Y et al (1997) Changes in alkaloid contents of reed canarygrass (Phalaris arundinacea L.) in relation to cultivar, growth stage, and plant parts. Tokyo Nogyo Daigaku Nogaku Shuho 42:122-126

Özgenç Ö, Durmaz S, Çelik G et al (2017) Comparative phytochemical analysis of volatile organic compounds by SPME-GC-FID/MS from six coniferous and nine deciduous tree barkspecies grown in Turkey. S Afr J Bot 113:23-28

Palo RT (1984) Distribution of birch (Betula spp.), willow (Salix spp.), and poplar (Populus spp.) secondary metabolites and their potential role as chemical defense against herbivores. J Chem Ecol 10:3

Pan YM, Zhang XP, Wang HS et al (2007) Antioxidant potential of ethanolic extract of Polygonum cuspidatum and application in peanut oil. Food Chem 105:1518-1524

Pan L, Sinden MR, Kennedy AH et al (2009) Bioactive constituents of Helianthus tuberosus (Jerusalem artichoke). Phytochem Lett 2:15-18

Parajuli R, Knudsen MT, Djomo SN et al (2017) Environmental life cycle assessment of producing willow, alfalfa and straw from spring barley as feedstocks for bioenergy or biorefinery systems. Sci Total Environ 586:226-240

Parveen I, Threadgill MD, Hauck B et al (2011) Isolation, identification and quantitation of hydroxycinnamic acid conjugates, potential platform chemicals, in the leaves and stems of Miscanthus $\times$ giganteus using LC-ESI-MS ${ }^{\mathrm{n}}$. Phytochemistry 72:2376-2384

Pasrija D, Anandharamakrishnan C (2015) Techniques for extraction of green teapolyphenols: a review. Food Bioprocess Technol 8:935-950

Patra JK, Kim ES, Oh K et al (2015) Bactericidal effect of extracts and metabolites of Robinia pseudoacacia L. on Streptococcus mutans and Porphyromonas gingivalis causing dental plaque and periodontal inflammatory diseases. Molecules 20:6128-6139

Pobłocka-Olech L, van Nederkassel AM, Vander Heyden Y et al (2007) Chromatographic analysis of salicylic compounds in different species of the genus Salix. J Sep Sci 30:2958-2966

Pobłocka-Olech L, Krauze-Baranowska M, Głód D et al (2010) Chromatographic analysis of simple phenols in some species from the genus Salix. Phytochem Anal 21:463-469

Popp D, Harms H, Sträuber H (2016) The alkaloid gramine in the anaerobic digestion process - inhibition and adaptation of the methanogenic community. Appl Microbiol Biot 100:7311-7322

Qi XL, Zhao P, Zhang YY et al (2018) Sesquiterpenes from stigma maydis (Zea mays) as a crop by-product and their potential neuroprotection and inhibitory activities of $\mathrm{A} \beta$ aggregation. Ind Crop Prod 121:411-417

Radulovic NS, Dordevic MR (2014) Chemical composition of the tuber essential oil from Helianthus tuberosus L. (Asteraceae). Chem Biodiver 11:427-437
Rathahao-Paris E, Alves S, Junot C, Tabet JC (2016) High resolution mass spectrometry for structural identification of metabolites in metabolomics. Metabolomics 12:10. https:// doi.org/10.1007/s11306-015-0882-8

Rosu AF, Bita A, Calina D et al (2012) Synergic antifungal and antibacterial activity of alcoholic extract of the species Robinia pseudoacacia L. (Fabaceae). Eur J Hosp Pharm 19:216-220

Rudman P (1963) The causes of natural durability in timber. XI.Some tests on the fungal toxicity of wood extractives and relatedcompounds. Holzforschung 77:54-57

Sacała E (2011) Miscanthus-unusual grass: biochemical and physiological characteristic: a review. Ecol Chem Eng 18:1615-1624

Sanz M, Fernandez de Simon B, Esteruelas E et al (2011) Effect of toasting intensity at cooperage on phenolic compounds in acacia (Robinia pseudoacacia) heartwood. J Agric Food Chem 59:3135-3145

Sanz M, Fernández de Simón B, Esteruelas E et al (2012) Polyphenols in red wine aged in acacia (Robinia pseudoacacia) and oak (Quercus petraea) wood barrels. Anal Chim Acta 732:83-90

Sarath G, Baird LM, Vogel KP et al (2007) Internode structure and cell wall composition in maturing tillers of switchgrass (Panicum virgatum L.). Bioresour Technol 98:2985-2992

Schwartz LM, Wooda AJ, Gibson DJ (2014) Trigonelline accumulation in leaves of Panicum virgatum seedlings. Nat Prod Commun 9:1163-1166

Sène M, Gallet C, Dorè T (2001) Phenolic compounds in a sahelian sorghum (Sorghum bicolor) genotype (CE145-66) and associated soils. J Chem Ecol 27:81-92

Sergent T, Kohnen S, Jourez B, Beauve C, Schneider YJ, Vincke C (2014) Characterization of black locust (Robinia pseudoacacia L.) heartwood extractives: identification of resveratrol and piceatannol. Wood Sci Technol 48:1005-1017

Shara M, Stohs SJ (2015) Efficacy and safety of white willow bark (Salix alba) extracts. Phytother Res 29:1112-1116

Skrigan AI, Vinokurov II (1970) Phenolic glucosides and flavonoids of willow bark. Issled Prir Sin Polim Mater IkhIspol'z, pp 37-45

Soltys D, Gniazdowska A, Bogatek R (2010) Sorgoleone-the main allelopathic compound from sorghum. Kosmos 59:567-579

Song JH, Kim SK, Chang KW et al (2006) In vitro inhibitory effects of Polygonum cuspidatum on bacterial viability and virulence factors of Streptococcus mutans and Streptococcus sobrinus. Arch Oral Biol 51:1131-1140

Song Y, Oh C, Bae HJ (2017) Simultaneous production of bioethanol and value-added D-psicose from Jerusalem artichoke (Helianthus tuberosus L.) tubers. Bioresour Technol 244:1068-1072

Steppuhn A, Gase K, Krock B et al (2004) Nicotine's defensive function in nature. PLoS Biol 2:217

Stolarski MJ, Krzyzaniak M, Łuczynski M et al (2015) Lignocellulosic biomass from short rotation woody crops as a feedstock for second-generation bioethanol production. Ind Crops Prod 75:66-75

Strašil Z, Kára J (2010) Study of knotweed (Reynoutria) as possible phytomass resource for energy and industrial utilization. Res Agric Engin 56:85-91 
Syrov WN, Chušbaktova ZA, Davidjanc ES (1992) The triterpene glicosides of Silphium perfoliatum L. hypolipidaemic activity of silphiozyd. Chim Farm Żurnal 26:66-69

Tchone M, Barwald G, Annemuller G et al (2006) Separation and identification of phenolic compounds in Jerusalem artichoke (Helianthus tuberosus L.). Sci Des Aliments 26:394-408

Techer D, Laval-Gilly P, Henry S et al (2011) Contribution of Miscanthus $\times$ giganteus root exudates to the biostimulation of PAH degradation: an in vitro study. Sci Total Environ 409:4489-4495

Techer D, D'InnocenzoM Laval-GillyP et al (2012) Assessment of Miscanthus $\times$ giganteus secondary root metabolites for the biostimulation of PAH-utilizing soil bacteria. Appl Soil Ecol 62:142-146

Tian FF, Mac Laughlin JL (2000) Bioactive flavonoids from black locust tree, Robinia pseudoacacia. Pharm Biol 38:229-234

Tian F, Chang CJ, Grutzner JB et al (2001) Robinlin: a novel bioactive homo-monoterpene from Robinia pseudoacacia L. (Favaceae). Bioorg Med Chem Lett 11:2603-2606

Tsakalova M, Yang A, Kokossis AC (2014) A systems approach for the holistic screening of second generation biorefinery paths for energy and bio-based products. Comput Aided Chem Eng 33:205-210

Ucisik AS, Trapp S (2006) Uptake, removal, accumulation, and phytotoxicity of phenol in Willow trees (Salix viminalis). Environ Toxicol Chem 25:2455-2460

Vastano BC, Chen Y, Zhu N et al (2000) Isolation and identification of stilbenes in two varieties of Polygonum cuspidatum. J Agric Food Chem 48:253-256

Vazquez-Olivo G, López-Martínez LX, Contreras-Angulo L et al (2017) Antioxidant capacity of lignin and phenolic compounds from corn stover. Waste Biom Valor 10:1-8

Veitch NC, Elliott PC, Kite GC et al (2010) Flavonoid glycosides of the black locust tree, Robinia pseudoacacia (Leguminosae). Phytochemistry 71:479-486

Villaverde JJ, Domingues RM, Freire CS et al (2009) Miscanthus $x$ giganteus extractives: a source of valuable phenolic compounds and sterols. J Agric Food Chem 57:3626-3631

Villaverde JJ, De Vega A, Ligero P et al (2010) Miscanthus $x$ giganteus bark organosolv fractionation: fate of lipophilic components and formation of valuable phenolic by products. J Agric Food Chem 58:8279-8285

Vrchotova N, Šerá B, Tř́íska J (2007) The stilbene and catechin content of the spring sprouts of Reynoutria species. Acta Chromatogr 19:21-28

Wang LJ (2013) Production of bioenergy and bioproducts from food processing wastes: a review. Trans ASABE 56:217-230

Wang LC, Yu YQ, Fang M et al (2014) Antioxidant and antigenotoxic activity of bioactive extracts from corn tassel. J Huazhong Univ Sci Technol 34:131-136

Wang Z, Liu Y, Wei J et al (2016) A method for making salicin from Salix alba bark. CN 105348336 A 20160224

Wei W, Wu K, Qin Y et al (2001) Intergeneric protoplast fusion between Kluyveromyces and Saccharomyces cerevisiae to produce sorbitol from Jerusalem artichokes. Biotechnol Lett 23:799-803
Weston LA, Barney JN, DiTommaso A (2005) A review of the biology and ecology three invasive perennials in New York State: Japanese knotweed (Polygonum cuspidatum), mugwort (Artemisia vulgaris) and pale swallowwort (Vincetoxicum rossicum). Plant Soil 277:53-69

Woods DL, Clark KW (1971) Genetic control and seasonal variation of some alkaloids in reed canarygrass. Can J Plant Sci 51:323-329

Woods DL, Hovin AW, Marten GC (1979) Seasonal variation of hordenine and gramine concentrations and their heritability in reed canarygrass. Crop Sci 19:853-857

Xiao K, Xuan L, Xu Y et al (2000) Stilbene glycoside sulfates from Polygonum cuspidatum. J Nat Prod 63:1373-1376

Xiao K, Xuan LJ, Xu YM et al (2003) Studies on the chemical constituents of Polygonum cuspidatum. Chin Pharm J 38:12-14

Yaeghoobi-Khanghahi F, Kazemi-Tabar SK, Gholipour A et al (2014) GC-MS analysis of the methanolic extract of Jerusalem artichoke (Helianthus tuberosus) tubers. Int J Biosci 5:156-161

Yamaguchi F, Nozue M, Yasuda H et al (2000) Effects of temperature on the pattern of anthocyanin accumulation in seedlings of Polygonum cuspidatum. J Plant Res 113:71-77

Yang F, Zhang T, Ito Y (2001) Large-scale separation of resveratrol, anthraglycoside A and anthraglycoside B from Polygonum cuspidatum Sieb. et Zucc by high-speed counter-current chromatography. J Chromatogr A 919:443-448

Yang L, He QS, Corscadden K et al (2015) The prospects of Jerusalem artichoke in functional food ingredients and bioenergy production. Biotechnol Rep 5:77-88

Yu P, Zhang H (2011) Simultaneous analysis of 17 compounds from extract of Giant knotweed R. by HPLC-ESI-MS. Shenyang Yaoke Daxue Xuebao 28:963-968

Yuan YW (1981) The bioactive compounds and their pharmacological action of Robinia L. Foreign Med Sci 6:332-334

Yuan X, Yang Q (2017) Simultaneous quantitative determination of 11 sesquiterpene lactones in Jerusalem artichoke (Helianthus tuberosus L.) leaves by ultra-high performance liquid chromatography with quadrupole time-offlight mass spectrometry. J Sep Sci 40:1457-1464

Yuan X, Gao M, Wang K et al (2008) Analysis of chlorogenic acids in Helianthus tuberosus Linn leaves using high performance liquid chromatography-mass spectrometry. Chin J Chromatogr 26:335-338

Yuan X, Gao M, Xiao H et al (2012) Free radical scavenging activities and bioactive substances of Jerusalem artichoke (Helianthus tuberosus L.) leaves. Food Chem 133:10-14

Yuan XY, Cheng MC, Gao MZ et al (2013) Cytotoxic constituents from the leaves of Jerusalem artichoke (Helianthus tuberosus L.) and their structure-activity relationships. Phytochem Lett 6:21-25

Zabka M, Pavela R, Gabrielova-Slezakova L (2011) Promising antifungal effect of some Euro-Asiatic plants against dangerous pathogenic and toxinogenic fungi. J Sci Food Agric 91:492-497

Zhang X, Thuong PT, Jin W et al (2005) Antioxidant activity of anthraquinones and flavonoids from flowers of Reynoutria sachalinensis. Arch Pharm Res 28:22-27 
Zhang W, Jia Y, Huang Q et al (2007) Simultaneous determination of five major compounds in Polygonum cuspidatum by HPLC. Chromatographia 66:685-689

Zhang ZY, Dai GH, Zhuge YY, Li YB (2008) Protective effect of Robinia pseudoacacia Linn extracts against cucumber powdery mildew fungus, Sphaerotheca fuliginea. Crop Prot 27:920-925
Zhu Z, Simister R, Bird S et al (2015) Microwave assisted acid and alkali pretreatment of Miscanthus biomass for biorefineries. AIMS Bioeng 2:449-468

Publisher's Note Springer Nature remains neutral with regard to jurisdictional claims in published maps and institutional affiliations. 